SR 229

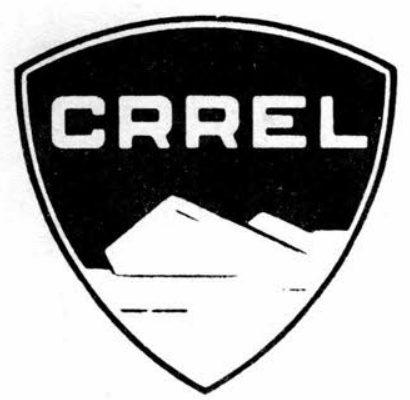

Special Report 229

HOOK ANCHOR TESTS

IN FROZEN AND UNFROZEN GROUND

Austin Kovacs

May 1975

\author{
PREPARED FOR \\ U.S. ARMY MATERIEL COMMAND \\ BY \\ CORPS OF ENGINEERS, U.S. ARMY \\ COLD REGIONS RESEARCH AND ENGINEERING LABORATORY \\ HANOVER, NEW HAMPSHIRE
}


The findings in this report are not to be construed as an official Department of the Army position unless so designated by other authorized documents. 


\begin{tabular}{|c|c|c|}
\hline \multicolumn{2}{|c|}{ REPORT DOCUMENTATION PAGE } & \multirow{2}{*}{$\begin{array}{c}\text { READ INSTRUCTIONS } \\
\text { BEFORE COMPLETING FORM } \\
\text { 3. RECIPIENT'S CATALOG NUMBER }\end{array}$} \\
\hline $\begin{array}{l}\text { 1. REPORT NUMBER } \\
\text { Special Report } 229\end{array}$ & 2. GOVT ACCESSION NO. & \\
\hline \multirow{2}{*}{\multicolumn{2}{|c|}{$\begin{array}{l}\text { 4. TITLE (and Subtitle) } \\
\text { HOOK ANCHOR TESTS IN FROZEN AND UNFROZEN GROUND }\end{array}$}} & 5. TYPE OF REPORT \& PERIOD COVERED \\
\hline & & 6. PERFORMING ORG. REPORT NUMBER \\
\hline \multicolumn{2}{|l|}{$\begin{array}{l}\text { 7. AUTHOR(s) } \\
\text { Austin Kovacs }\end{array}$} & 8. CONTRACT OR GRANT NUMBER(s) \\
\hline \multicolumn{2}{|c|}{$\begin{array}{l}\text { 9. PERFORMING ORGANIZATION NAME AND ADDRESS } \\
\text { U.S. Army Cold Regions Research and Engineering Laboratory } \\
\text { Hanover, New Hampshire } 03755\end{array}$} & $\begin{array}{l}\text { 10. PROGRAM ELEMENT, PROJECT, TASK } \\
\text { AREA \& WORK UNIT NUMBERS } \\
\text { DA Project } 1 \text { T062112A130 } \\
\text { Work Unit } 001\end{array}$ \\
\hline \multirow[t]{2}{*}{ 11. CONTROLLING OFFICE NAME AND ADDRESS } & \multirow[t]{2}{*}{$\bar{*}$} & $\begin{array}{l}\text { 12. REPORT DATE } \\
\text { May } 1975\end{array}$ \\
\hline & & $\begin{array}{l}\text { 13. NUMBER OF PAGES } \\
35\end{array}$ \\
\hline \multirow{2}{*}{\multicolumn{2}{|c|}{$\begin{array}{l}\text { 14. MONITORING AGENCY NAME \& ADDRESS(if different from Controlling Office) } \\
\text { U.S. Army Materiel Command }\end{array}$}} & 15. SECURITY CLASS. (of this roport) \\
\hline & & $\begin{array}{l}\text { 15a. DECLASSIFICATION/DOWNGRADING } \\
\text { SCHEDULE }\end{array}$ \\
\hline
\end{tabular}

Approved for public release; distribution unlimited.

17. DISTRIBUTION STATEMENT (of the abstract ontered in Block 20, if different from Report)

18. SUPPLEMENTARY NOTES

19. KEY WORDS (Continue on reverse side if necessary and identify by block number)

Anchors (structures)

Bridge anchorages

Cold weather construction

Foundations

\section{ABSTRACT (Continue on reverse side if necoseary and tdentify by block number)}

The findings of an exploratory study of the holding capacity of hook anchors in frozen and unfrozen ground are presented. Testing revealed that hook anchors are capable of being driven and retrieved from frozen silt and that their holding capacity was reasonably high in comparison to their size. Hook anchor capacity in the frozen silt at $-2^{\circ} \mathrm{C}$ was found to be three times higher than in the unfrozen silt. 


\section{PREFACE}

This report presents the findings of an exploratory study of hook anchors load tested in both frozen and unfrozen ground. The study was performed by the U.S. Army Cold Regions Research and Engineering Laboratory (USA CRREL) for the U.S. Army Materiel Command under DA Project 1T062112A130, Cold Regions Research, Work Unit 001, Military Anchorages in Frozen Materials.

The field work was conducted by Austin Kovacs, Research Civil Engineer, and Bruce McKelvy and Rodolfo Victorio, Research Assistants, Foundations and Materials Research Branch, Experimental Engineering Division; and John Kalafut, Electrical Engineer, Technical Services Division. Technical review of the report was performed by Henry Stevens, Research Civil Engineer, Foundations and Materials Research Branch, Experimental Engineering Division.

The contents of this report are not to be used for advertising, publication, or promotional purposes. Citation of trade names does not constitute an official endorsement or approval of the use of such commercial products. 
CONTENTS

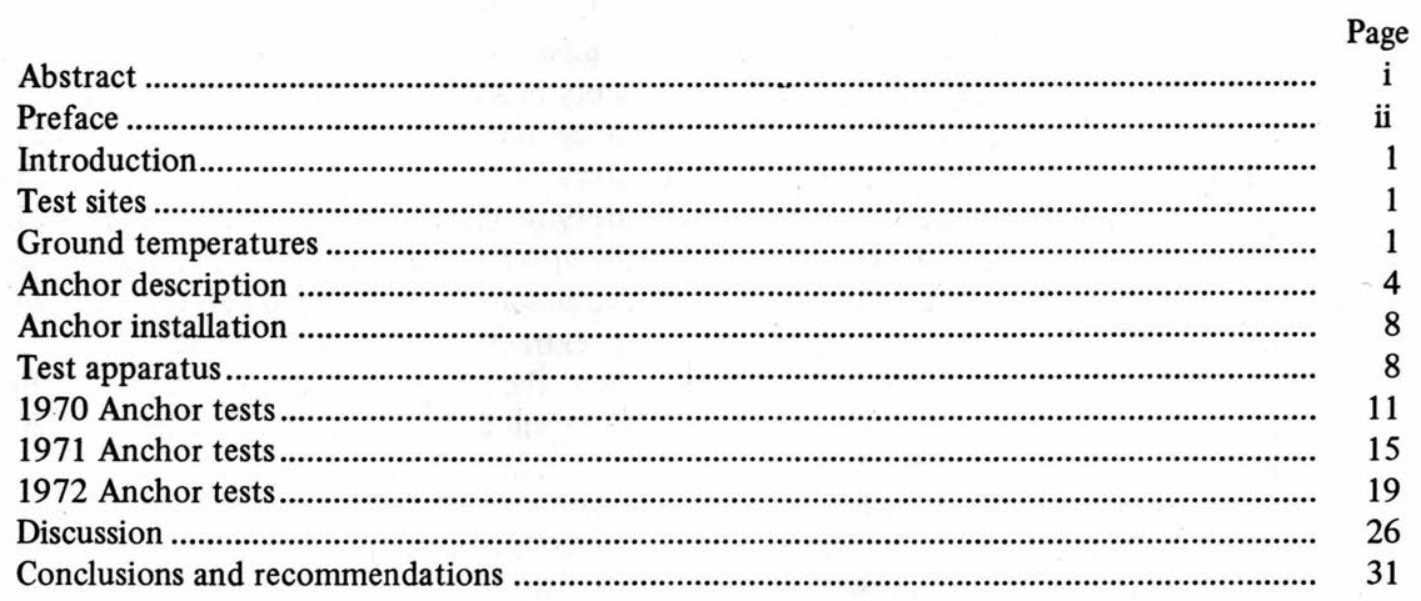

\section{ILLUSTRATIONS}

Figure

1. Grain size distribution of silt at the 1971 Hanover test site....

2. Soil water content and density at the Hanover test site on 6 March and 6 June $1972 \ldots$

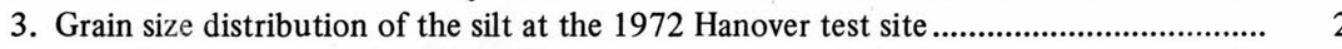

4. Configuration of hook anchors tested ........................................................................ 5

5. View of a $5 / 16$ in. diameter hook anchor with 12 in. shank ........................................ 5

6. View of the GP-112/G guy stake .................................................................................. 5

7. Horizontal and end views during load test of the Grizzly Mini Stake.............................. 8

8. Dimensions of GP-112/G stake .................................................................................. 8

9. Manufacturer's recommended procedure for driving and retrieving hook anchors......... 9

10. Loading arrangement used during the 1970 hook anchor tests in Fairbanks................. $\quad 10$

11. Pneumatic ram loading system used during the 1971 and 1972 anchor tests................. 10

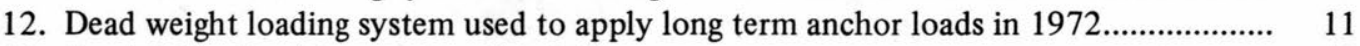

13. Load-deflection history of anchor $1-\mathrm{H}$....................................................................... 12

14. Load-deflection history of anchor $2-\mathrm{H}$.................................................................... $\quad 12$

15. Load-deflection history of anchor 3-H ..................................................................... 12

16. Typical deformation sustained by hook anchors drawn out of frozen ground .............. 13

17. Load-deflection history of anchor $4-\mathrm{H}$.......................................................................... 13

18. Load-deflection history of anchor $5-\mathrm{H}$................................................................ 13

19. Load-deflection history of anchor $6-\mathrm{H}$..................................................................... $\quad 14$

20. Configuration of anchor 6-H after it was drawn out of the frozen silt of the Fairbanks

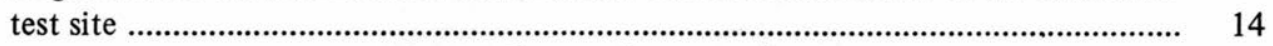

21. Test ground temperatures and load-deflection history of anchor 1-J ........................... 15

22. Test ground temperatures and load-deflection history of anchor 2-J ........................... 16

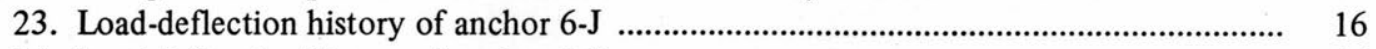

24. Load-deflection history of anchor 7-J ..................................................................... 16

25. Load-deflection history of anchor 9-J .......................................................................... 17 
Figure Page

26. Load-deflection history of anchor 11-J ......................................................................... 17

27. Load-deflection history of anchor 12-J ........................................................................ 17

28. Load-deflection history of anchor 13-J ....................................................................... 18

29. Load-deflection history of anchor 14-J ........................................................................ 18

30. Post test configuration of an anchor with its included angle increased beyond $90^{\circ}$ as a result of being drawn out of its frozen ground embedment ....................................... 19

31. Test ground temperatures and load-deflection history of anchor 1-B ............................ 20

32. Test ground temperatures and load-deflection history of anchor 2-B ............................ 20

33. Test ground temperatures and load-deflection history of anchor 5-B ............................ 21

34. Test ground temperatures and load-deflection history of anchor 7-B ............................ 21

35. Examples of hook anchor deflection at moderately high loading ................................. 23

36. Views of hook anchors not loaded to complete extraction from frozen ground............. 24

37. Typical configuration of hook anchors complutely extracted from frozen ground......... 25

38. Examples of hook anchors which failed at the elbow when loaded ................................ 26

39. Configuration of GM stakes at the cessation of load testing ............................................ 26

40. Driving of hook anchor under field conditions .............................................................. 27

41. Final drive seating of hook anchor after tent guy has been attached ............................. 27

42. Location of hook anchors used with Canadian Armed Forces Modular tent.................. 27

43. Graphic presentation of test results showing anchor load capacity vs anchor size and vs the frozen and unfrozen ground conditions existing during the tests reported ...... $\quad 30$

44. Generalized movement of hook anchors under increased loading................................... 30

TABLES

Table

I. Ground temperature data ............................................................................................

II. Anchor test data ...................................................................................................... 6

III. Properties of guy stakes and anchors ..................................................................... 28

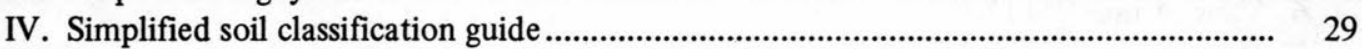




\title{
HOOK ANCHOR TESTS IN FROZEN AND UNFROZEN GROUND
}

by

\author{
Austin Kovacs
}

\section{Introduction}

Anchoring is the technique used to support and stabilize guyed structures. Portable structures which are dismantled and moved to different sites present a complex tie-down problem. This results from the demand often placed upon the anchor system to be in fact a universal system capable of providing reliable anchorage under a wide range of soil conditions. Therefore, for many portable structures two or more anchor types are provided to contend with various soil conditions. Selection of anchors is based upon such factors as weight, ease of emplacement, reusability and holding capacity.

Providing anchorage in frozen ground is often a very difficult task due to the ground's resistance to displacement or disengagement. The strength of frozen ground varies markedly, being dependent upon such parameters as soil type, frozen water content and distribution and temperature. It is not uncommon to hear of instances where anchorage was not adequately provided because the anchor was structurally unfit for the hard driving required to emplace it, or the ground was simply too resistant for anchor penetration. It is also common to hear of situations where anchors had to be abandoned because it was impossible to extract them from the frozen ground in which they were embedded.

This report presents the findings of an exploratory study of the holding capacity of hook anchors (trade name Anker) in both frozen and unfrozen silt. Tne anchor is a relatively new modification of an old concept. It was selected for testing because it appeared structurally robust and particularly suited for frozen ground installation and retrieval.

\section{Test sites}

While another study was being conducted in Alaska in March 1970, time allowed for initial load testing of the hook anchor. The tests were conducted at the USA CRREL Alaska Field Station (now the Alaskan Projects Office) in Fairbanks. The soil at the test site was a silt having a bulk density of $88 \mathrm{lb} / \mathrm{ft}^{3}$, a dry density of $60 \mathrm{lb} / \mathrm{ft}^{3}$ and a moisture content of $45 \%$.

In 1971 and 1972 additional load testing of the hook anchor was conducted in frozen and unfrozen silt behind the CRREL facility in Hanover, N.H. The 1971 anchor tests were conducted in soil having a bulk density of $110 \mathrm{lb} / \mathrm{ft}^{3}$, a dry density of $86 \mathrm{lb} / \mathrm{ft}^{3}$ and a moisture content of $29 \%$. The soil's grain size gradation is shown in Figure 1. As would be expected, soil density and water content varied during the long winter to summer test season of 1972. An indication of the soil density and water content with depth during the winter and summer tests is given in Figure 2. The representative grain size distribution of the soil is presented in Figure 3.

\section{Ground temperatures}

At the Fairbanks test site the soil temperature 5 in. below the surface was recorded with a thermocouple. During the tests the soil at this depth remained at $-2^{\circ} \mathrm{C}$. Soil temperatures at the Hanover test site were obtained to the nearest $0.01^{\circ} \mathrm{C}$ from the thermocouples installed $1,6,12$ and $18 \mathrm{in}$. below the ground surface. The temperature readings obtained are presented to the nearest $0.1^{\circ} \mathrm{C}$ in Table I. 


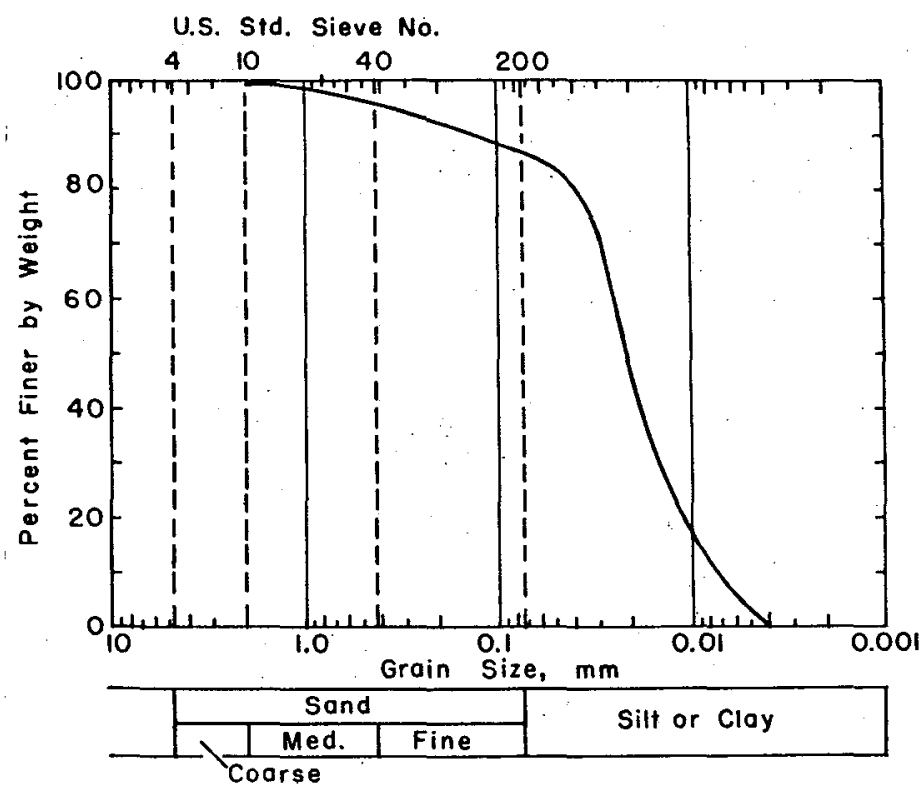

Figure 1. Grain size distribution of silt at the 1971 Hanover test site.
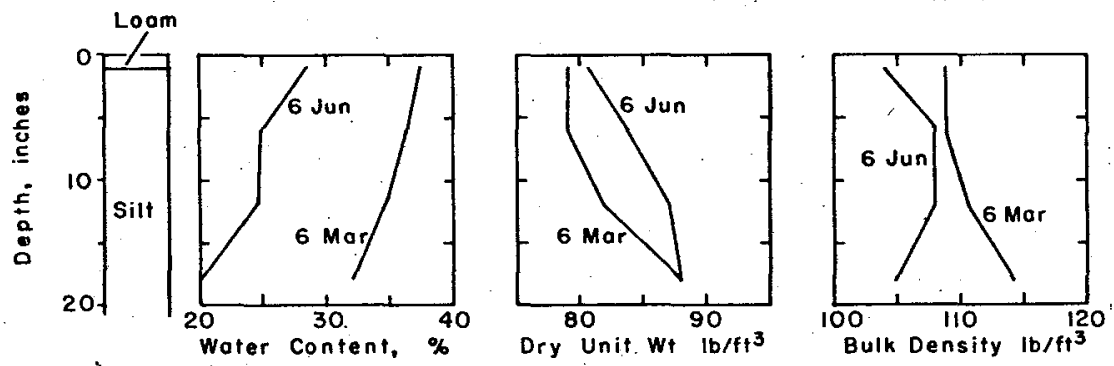

Figure 2. Soil water content and density at the Hanover test site on 6 March and 6 June 1972.

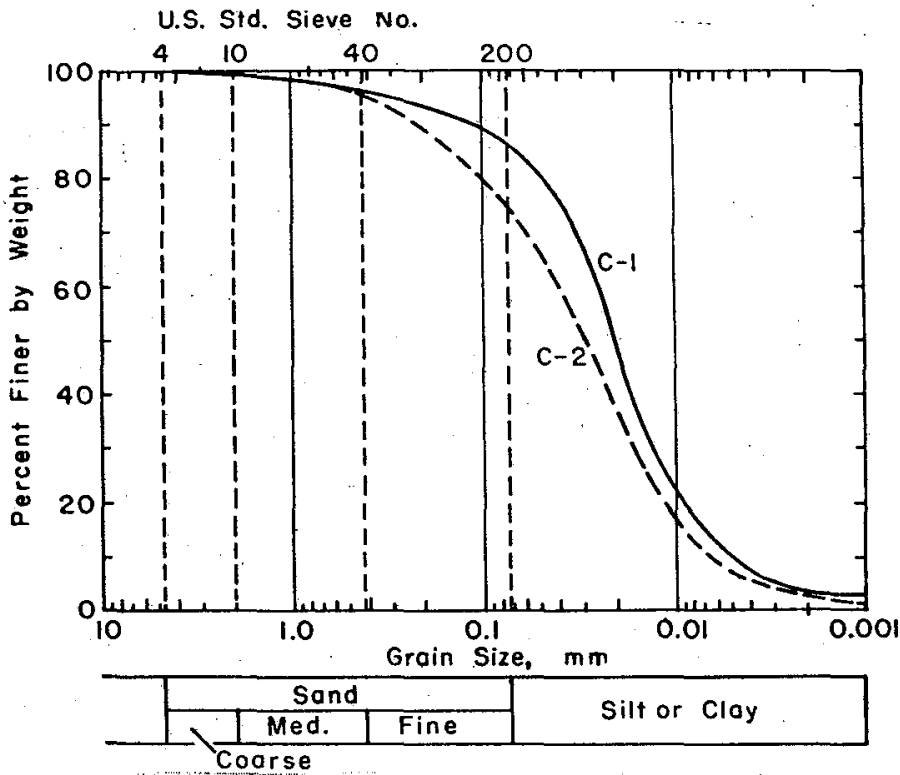

Figure 3. Grain size distribution of the silt at the 1972 Hanover test site. (Curves $C-1$ and $C-2$ represent two test site soils at two different locations.) 
Table I. Ground temperature data.

Average of 8 a.m. and 4 p.m. ground temperatures $\left({ }^{\circ} \mathrm{C}\right)$.

\begin{tabular}{|c|c|c|c|c|}
\hline \multirow[b]{2}{*}{ Date } & \multicolumn{4}{|c|}{ Depth, in. } \\
\hline & 1 & 6 & 12 & 18 \\
\hline 19 Feb 1971 & -0.7 & -1.2 & -1.7 & -1.6 \\
\hline 22 & -1.2 & -1.2 & -1.2 & -1.0 \\
\hline 23 & -2.0 & -1.7 & -1.2 & -0.9 \\
\hline 24 & -1.5 & -1.5 & -1.3 & -1.0 \\
\hline 25 & -2.6 & -2.5 & -1.3 & -1.6 \\
\hline 26 & -2.4 & -2.3 & -2.0 & -1.2 \\
\hline $1 \mathrm{Mar}$ & -0.2 & -0.5 & -0.7 & -0.7 \\
\hline 2 & -1.0 & -0.7 & -0.7 & -0.3 \\
\hline 3 & -0.2 & -0.5 & -0.7 & -0.6 \\
\hline 4 & -0.3 & -0.5 & -0.6 & -0.6 \\
\hline 5 & -0.7 & -0.6 & -0.6 & -0.6 \\
\hline 8 & -2.0 & -0.9 & -0.7 & -0.6 \\
\hline 9 & -5.4 & -3.3 & -1.0 & -0.6 \\
\hline 10 & -5.1 & -4.4 & -3.2 & -1.3 \\
\hline 11 & -2.6 & -2.7 & -2.3 & -1.8 \\
\hline 12 & -1.3 & -1.7 & -1.6 & -1.2 \\
\hline 13 & -2.5 & -2.3 & -1.6 & -1.1 \\
\hline 15 & -0.3 & -0.8 & -1.1 & -1.0 \\
\hline 16 & -0.4 & -0.4 & -0.8 & -0.8 \\
\hline 17 & -0.2 & -0.5 & -0.8 & -0.8 \\
\hline 18 & -0.2 & -0.4 & -0.7 & -0.7 \\
\hline 23 & -0.1 & -0.3 & -0.4 & -0.4 \\
\hline 24 & -2.9 & -1.0 & -0.4 & -0.4 \\
\hline 25 & -0.2 & -2.3 & -0.6 & -0.5 \\
\hline 26 & -6.9 & -3.4 & -0.7 & -0.4 \\
\hline 29 & -2.6 & -0.4 & -0.7 & -0.6 \\
\hline 30 & -0.1 & -0.4 & -0.6 & -0.6 \\
\hline 31 & -0.1 & -0.3 & -0.6 & -0.5 \\
\hline $1 \mathrm{Apr}$ & -2.9 & -0.2 & -0.5 & -0.7 \\
\hline 2 & -3.4 & -0.2 & -0.5 & -0.5 \\
\hline 5 & -0.2 & -0.1 & -0.7 & -0.7 \\
\hline $11 \mathrm{Jan} 1972$ & -0.2 & -0.1 & -0.2 & -0.2 \\
\hline 12 & -0.2 & -0.3 & -0.3 & 0 \\
\hline 13 & -0.8 & -0.6 & -0.3 & 0 \\
\hline 14 & -0.2 & -0.3 & -0.2 & 0 \\
\hline 17 & -3.4 & -2.9 & $-3,0$ & -1.9 \\
\hline 18 & -3.2 & -3.2 & -3.2 & -2.0 \\
\hline 19. & -1.0 & -1.6 & -1.4 & -1.0 \\
\hline 20 & -2.0 & -1.8 & -1.6 & -1.0 \\
\hline 21 & -2.0 & -1.9 & -1.6 & -1.2 \\
\hline 24 & -0.1 & -0.2 & -0.3 & -0.1 \\
\hline 25 & 0 & 0 & -0.2 & -0.2 \\
\hline 26 & -5.0 & -5.0 & -1.5 & -0 \\
\hline 27 & -5.6 & -4.7 & -3.6 & -0.5 \\
\hline 28 & -5.5 & -4.8 & -3.8 & -1.0 \\
\hline 31 & -7.0 & -5.2 & -2.9 & -1.2 \\
\hline $1 \mathrm{Feb}$ & -6.9 & -5.8 & -3.5 & -1.4 \\
\hline 2 & -5.4 & -4.6 & -3.4 & -2.0 \\
\hline 3 & -4.6 & -3.8 & -3.1 & -1.8 \\
\hline 4 & -2.0 & -1.9 & -2.0 & -1.7 \\
\hline 8 & -5.8 & -5.4 & -4.0 & -2.5 \\
\hline 9 & -5.8 & -5.2 & -4.5 & -2.2 \\
\hline 11 & -6.3 & -5.1 & -4.6 & -2.1 \\
\hline 14 & -2.4 & -0.8 & -0.8 & -0.9 \\
\hline 15 & -0.5 & -0.7 & -0.8 & -0.1 \\
\hline 16 & -1.1 & -0.8 & -0.8 & -0.4 \\
\hline 17 & -2.0 & -1.3 & -1.0 & -0.7 \\
\hline 18 & -1.0 & -1.0 & -0.2 & -0.2 \\
\hline
\end{tabular}


Table I (cont'd). Ground temperature data.

Average of 8 a.m. and 4 p.m. ground temperatures $\left({ }^{\circ} \mathrm{C}\right)$.

\begin{tabular}{|c|c|c|c|c|}
\hline \multirow[b]{2}{*}{ Date } & \multicolumn{4}{|c|}{ Depth, in. } \\
\hline & 1 & 6 & 12 & 18 \\
\hline 22 Feb 1972 & -4.0 & -3.4 & -3.2 & -2.7 \\
\hline 22 & -5.7 & -5.6 & -5.1 & -3.5 \\
\hline 25 & -4.0 & -4.1 & -3.4 & -3.0 \\
\hline 28 & -2.3 & -1.3 & -1.2 & -0.9 \\
\hline 29 & -0.5 & -0.8 & -1.0 & -0.9 \\
\hline $1 \mathrm{Mar}$ & -0.2 & -0.8 & -1.0 & -1.0 \\
\hline 2 & 0 & -2.0 & -0.4 & -0.6 \\
\hline 3 & -0.5 & -0.4 & -0.6 & -0.5 \\
\hline 6 & 0 & 0 & -0.4 & -0.6 \\
\hline 7 & -0.2 & -0.2 & -0.4 & -0.5 \\
\hline 8 & 0 & -0.1 & -0.3 & -0.4 \\
\hline 9 & 0 & -0.2 & -0.7 & -0.4 \\
\hline 10 & -1.6 & -1.2 & -0.8 & -0.6 \\
\hline 13 & -0.3 & -0.1 & -0.4 & -0.5 \\
\hline 14 & -0.2 & -0.2 & -0.4 & -0.5 \\
\hline 15 & -1.4 & -1.6 & -1.4 & -1.0 \\
\hline 16 & -1.3 & -1.1 & -0.9 & -0.8 \\
\hline 17 & -0.5 & -0.6 & -0.5 & -0.5 \\
\hline 20 & -0.7 & -0.4 & -0.5 & -0.6 \\
\hline 21 & -0.4 & -0.4 & -0.4 & -0.5 \\
\hline 22 & -0.1 & -0.1 & -0.3 & -0.4 \\
\hline 23 & +0.8 & -0.2 & -0.3 & -0.5 \\
\hline 27 & 0 & -0.2 & -0.1 & -0.3 \\
\hline 28 & +0.1 & -0.1 & -0.2 & -0.3 \\
\hline 29 & +0.1 & -0.1 & -0.2 & -0.3 \\
\hline 30 & +0.1 & +0.1 & -0.2 & -0.2 \\
\hline $3 \mathrm{Apr}$ & 0 & -0.2 & -0.2 & -0.3 \\
\hline & om thi & mpera & & \\
\hline
\end{tabular}

\section{Anchor description}

The hook anchor may be best described as having the shape of half a wire clothes hanger. A number of these anchors are shown in Figure 4 and a close-up view of a $5 / 16$-in.-diameter one with a shank length (that portion of the anchor driven into the ground) of 12 in. is shown in Figure 5. As can be seen in Figure 5 the arm of the anchor has a curved end. It is here that the guy wire or rope is attached to the anchor. The anchors are made of spring steel, and may be obtained with diameters ranging in $1 / 8$-in. increments from $1 / 8$ in. to $1 \frac{1}{4}$ in. and shank lengths from 5 in. to $3 \frac{1}{2} \mathrm{ft}$. The included angle between anchor arm and shank is either 30 or $45^{\circ}$.

While the hook anchor was the primary test anchor two other anchors underwent token testing. One was a military GP-112/G guy stake (Fig. 6) and the other was the Grizzly Mini Stake (GM) shown in Figure 7. The GP-112/G is a forged steel stake with the dimensions shown in Figure 8. The 12-in.-long GM stake is stamped from a $1 / 64$-in.-thick steel strip. The anchor is $U$-shaped, having a width of $3 / 4$ in. and a depth of $1 / 2$ in.

A list of the anchors tested along with information pertinent to each test is given in Table II. 


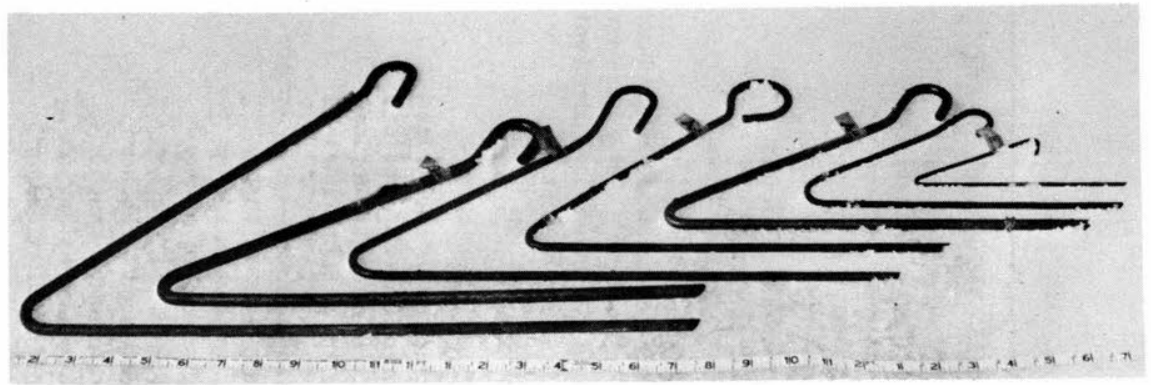

Figure 4. Configuration of hook anchors tested.

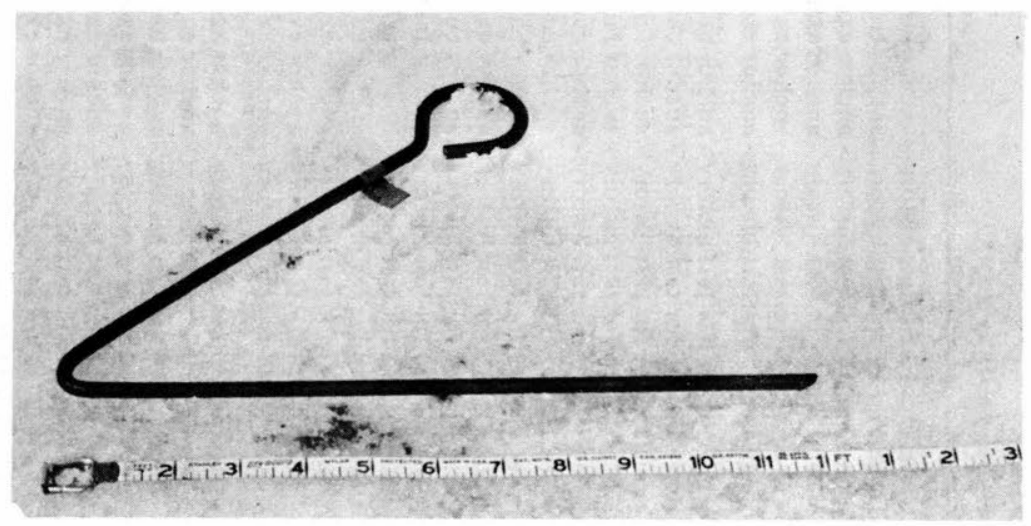

Figure 5. View of a 5/16 in. diameter hook anchor with 12 in. shank.

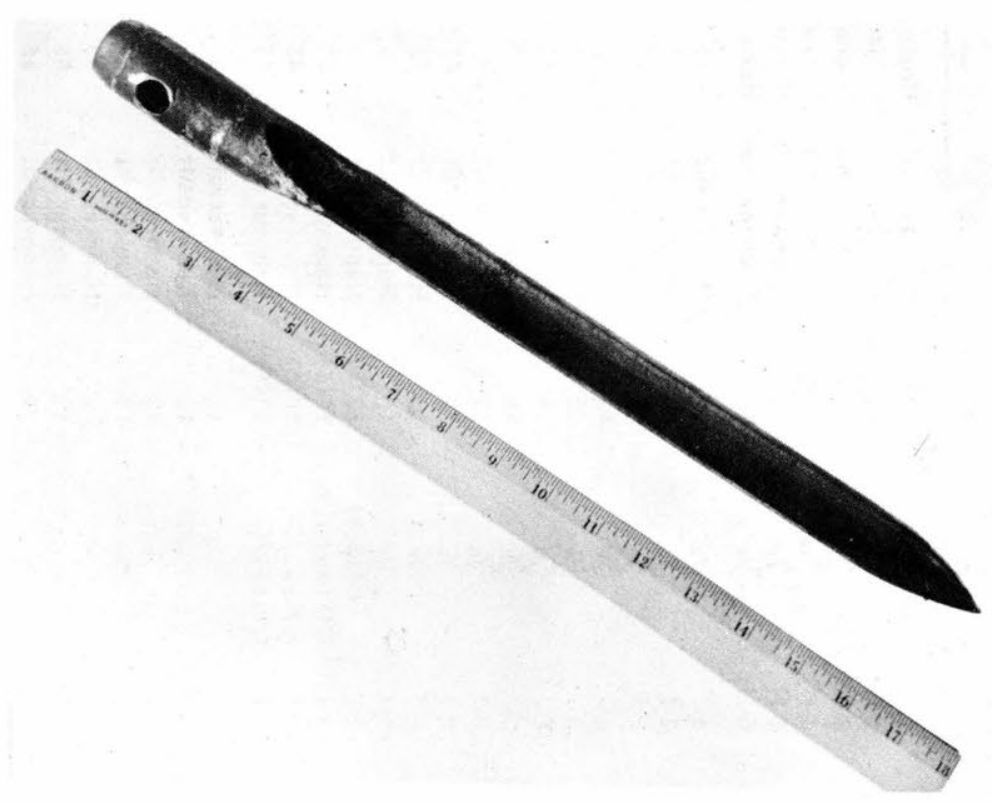

Figure 6. View of the GP-112/G guy stake. 
Table II. Anchor test data.

\begin{tabular}{|c|c|c|c|c|c|c|}
\hline Date & Test & $\begin{array}{c}\text { Anchor diam } \\
\text { (in.) }\end{array}$ & $\begin{array}{c}\text { Length* } \\
\text { (in.) }\end{array}$ & Soil & Load angle & $\begin{array}{c}\text { Max load } \\
(l b)\end{array}$ \\
\hline $29 \operatorname{Mar} 70$ & 1-H & $1 / 2$ & 18 & Fairbanks silt & Horizontal & 1000 \\
\hline $30 \operatorname{Mar} 70$ & $2 \cdot \mathrm{H}$ & $3 / 16$ & 9 & Fairbanks silt & Horizontal & 250 \\
\hline 30 Mar 70 & $3-\mathrm{H}$ & $3 / 16$ & 9 & Fairbanks silt & Horizontal & 250 \\
\hline 31 Mar 70 & 4-H & $3 / 16$ & 9 & Fairbanks silt & Horizontal & 250 \\
\hline 1 Apr 70 & $5-\mathrm{H}$ & $3 / 16$ & 9 & Fairbanks silt & Horizontal & 400 \\
\hline $1 \mathrm{Apr} 70$ & $6 \cdot \mathrm{H}$ & $1 / 2$ & 18 & Fairbanks silt & Horizontal & 1800 \\
\hline $18 \mathrm{Feb} 71$ & 1-J & $1 / 2$ & 18 & Hanover silt & $45^{\circ}$ & 1000 \\
\hline 1 Mar 71 & 2-J & $5 / 8$ & 18 & Hanover silt & $45^{\circ}$ & 1500 \\
\hline 15 Mar 71 & 3-J & $3 / 8$ & 12 & Hanover silt & $45^{\circ}$ & 250 \\
\hline 23 Mar 71 & 4-J & $3 / 8$ & 12 & Hanover silt & $45^{\circ}$ & 250 \\
\hline 29 Mar 71 & $5-\mathrm{J}$ & $5 / 3$ & 18 & Hanover silt & $45^{\circ}$ & 1000 \\
\hline 27 May 71 & 6-J & $5 / 8$ & 18 & Hanover silt & $45^{\circ}$ & 375 \\
\hline 9 Jun 71 & 7.J & $5 / 8$ & 18 & Hanover silt & $45^{\circ}$ & 375 \\
\hline 25 Jun 71 & 8-J & $3 / 8$ & 12 & Hanover silt & $45^{\circ}$ & 150 \\
\hline $2 \mathrm{Jul} 71$ & 9-J & $3 / 8$ & 12 & Hanover silt & $45^{\circ}$ & 150 \\
\hline $8 \mathrm{Jul} 71$ & $10-\mathrm{J}$ & $3 / 8$ & 12 & Hanover silt & $45^{\circ}$ & 75 \\
\hline $9 \mathrm{Jul} 71$ & $11-\mathrm{J}$ & $5 / 8$ & 18 & Hanover silt & $45^{\circ}$ & 500 \\
\hline 11 Aug 71 & $12-J$ & GMS(1) & $12(2)$ & Hanover silt & $45^{\circ}$ & 112 \\
\hline 19 Aug 71 & 13-J & GP-112/G(3) & $17(5)$ & Hanover silt & $45^{\circ}$ & 375 \\
\hline 25 Aug 71 & 14-J & GP-112/G & $17(5)$ & Hanover silt & $45^{\circ}$ & 250 \\
\hline 25 Aug 71 & $15-\mathrm{J}$ & $G P=112 / G$ & $17(5)$ & Hanover silt & $45^{\circ}$ & 300 \\
\hline $12 \mathrm{~J}$ an 72 & $1 \cdot B$ & $5 / 16$ & 12 & Hanover silt & $55^{\circ}$ & 250 \\
\hline $13 \mathrm{Jan} 72$ & $16-J$ & $\begin{array}{l}118 \\
5 / 16\end{array}$ & 12 & Hanover silt & $55^{\circ}$ & $575(4)$ \\
\hline $24 \mathrm{Jan} 72$ & 17-J & $s / 16$ & 12 & Hanover silt & $55^{\circ}$ & $450(4)$ \\
\hline $25 \mathrm{Jan} 72$ & $18-\mathrm{J}$ & $5 / 16$ & 12 & Hanover silt & $55^{\circ}$ & $380(4)$ \\
\hline $26 \mathrm{~J}$ an 72 & 2-B & $5 / 16$ & 12 & Hanover silt & $55^{\circ}$ & 450 \\
\hline $26 \operatorname{Jan} 72$ & 19-J & $5 / 26$ & 12 & Hanover silt & $55^{\circ}$ & $450(4)$ \\
\hline $29 J$ an 72 & 3-B & $3 / 16$ & 9 & Hanover silt & $55^{\circ}$ & 100 \\
\hline 9 Feb 72 & 20-J & $5 / 16$ & 12 & Hanover silt & $55^{\circ}$ & $450(4)$ \\
\hline $11 \mathrm{Feb} 72$ & 21-J & $1 / 4$ & 15 & Hanover silt & $55^{\circ}$ & $400(4)$ \\
\hline
\end{tabular}

See Fig. 13 for test history - anchor loaded to $1000 \mathrm{lb}$ to observe creep for $1 \mathrm{hr}$ See Fig. 14 for test history - anchor creep rate excessive

See Fig. 15 for test history - anchor extracted

See Fig. 17 for test history - anchor extracted

See Fig. 18 for test history - anchor extracted

See Fig. 19 for test history - anchor extracted

See Fig. 20 for test history - anchor bent- partially drawn out of ground

See Fig. 21 for test history - anchor cut into soil during extraction

See Fig. 21 for test history - anchor failed structurally at elbow

See Fig. 2:1 for test history - anchor failed structurally at elbow

See Fig. 21 for test history - anchor cut into soil during extraction - lever arm bent See Fig. 22 for test history - anchor cut into soil during extraction - lever arm bent See Fig. 23 for test history - anchor cut into soil during extraction - lever arm bent See Fig. 23 for test history - anchor extracted - soil displaced by shank

See Fig. 24 for test history - anchor cut into soil during extraction See Fig. 24 for test history - anchor failed at elbow

See Fig 25 for test history - lever arm bent - soil cut by shank

See Fig. 26 for test history - anchor extracted - soil crept under anchor load See Fig. 27 for test history - anchor extracted - soil crept under anchor load See Fig. 28 for test history - anchor extracted - soil crept under anchor load See Fig. 28 for test history - anchor extracted - soil crept under anchor load

See Fig. 30 for test history - anchor partially extracted - soil displaced by anchor See Fig. 30 for test history - anchor extracted - soil displaced by anchor See Fig. 30 for test history - anchor extracted - soil displaced by anchor See Fig. 30 for test history - anchor extracted - soil displaced by anchor See Fig. 31 for test history - anchor extracted - soil displaced by anchor See Fig. 31 for test history - anchor extracted - soil displaced by anchor See Fig. 31 for test history - anchor extracted - soil displaced by anchor 450(4) See Fig 31 for test history - anchor extracted - soil displaced by anchor 400(4) See Fig. 31 for test history - anchor extracted - soil displaced by anchor 
Table II (cont'd).

\begin{tabular}{|c|c|c|c|c|c|c|c|}
\hline Date & Test & $\begin{array}{c}\text { Anchor diam } \\
\text { (in.) }\end{array}$ & $\begin{array}{l}\text { Length* } \\
\text { (in.) }\end{array}$ & Soil & Load angle & $\begin{array}{c}\text { Max load } \\
(l b)\end{array}$ & Remarks \\
\hline 14 Feb 72 & 22-J & $5 / 16$ & 15 & Hanover silt & $55^{\circ}$ & $500(4)$ & See Fig. 31 for test history - anchor extracted - soil displaced by anchor \\
\hline $14 \mathrm{Feb} 72$ & 23-J & $1 / 4$ & 15 & Hanover silt & $55^{\circ}$ & $400(4)$ & See Fig. 31 for test history - anchor failed at elbaw \\
\hline $14 \mathrm{Feb} 72$ & $4-B$ & $3 / 46$ & 9 & Hanover silt & $55^{\circ}$ & 100 & See Fig: 31 for test history - anchor extracted - soil displaced by anchor \\
\hline $15 \mathrm{Feb} 72$ & $22-\mathrm{J}$ & $1 / 4$ & 15 & Hanover silt & $55^{\circ}$ & $400(4)$ & See Fig. 31 for test history - anchor extracted - soil displaced by anchor \\
\hline $15 \mathrm{Feb} 72$ & $25-\mathrm{J}$ & $1 / 4$ & 15 & Hanover silt & $55^{\circ}$ & $400(4)$ & See Fig. 31 for test history - anchor extracted - soil displaced by anchor \\
\hline 16 Feb 72 & 26-J & $5 / 46$ & 16 & Hanover silt & $55^{\circ}$ & $500(4)$ & See Fig. 31 for test history - anchor extracted - soil displaced by anchor \\
\hline 16 Feb 72 & $27-\mathrm{J}$ & $\begin{array}{l}1 / 16 \\
3 / 16\end{array}$ & 9 & Hanover silt & $55^{\circ}$ & $150(4)$ & See Fig. 31 for test history - anchor extracted - soil displaced by anchor \\
\hline $16 \mathrm{Feb} 72$ & $28-\mathrm{J}$ & $3 / 16$ & 9 & Hanover silt & $55^{\circ}$ & $150(4)$ & See Fig. 31 for test history - anchor extracted - soil displaced by anchor \\
\hline 16 Feb 72 & $5-\mathrm{B}$ & $5 / 16$ & 12 & Hanover silt & $55^{\circ}$ & 550 & See Fig. 32 for test history - anchor failed at elbow - soil displaced by anchor \\
\hline $17 \mathrm{Feb} 72$ & $29-\mathrm{J}$ & $5 / 16$ & 16 & Hanover silt & $55^{\circ}$ & $550(4)$ & See Fig. 32 for test history - anchor extracted - soil displaced by anchor \\
\hline $29 \mathrm{Feb} 72$ & $6-\mathrm{B}$ & $3 / 16$ & 9 & Hanover silt & $55^{\circ}$ & 100 & See Fig. 32 for test history - anchor extracted - soil displaced by anchor \\
\hline $2 \operatorname{Mar} 72$ & 7-B & $1 / 4$ & 15 & Hanover silt & $55^{\circ}$ & 400 & See Fig. 33 for test history - anchor extracted - soil displaced by anchor \\
\hline $14 \mathrm{Mar} 72$ & 8-B & $3 / 16$ & 9 & Hanover silt & $55^{\circ}$ & 100 & See Fig. 33 for test history - anchor extracted - soil displaced by anchor \\
\hline $17 \mathrm{Mar} 72$ & 9-B & $1 / 8$ & 6 & Hanover silt & $55^{\circ}$ & 45 & See Fig. 33 for test history - anchor extracted - soil displaced by anchor \\
\hline $20 \mathrm{Mar} 72$ & $10-\mathrm{B}$ & GMS & 12 & Hanover silt & $55^{\circ}$ & 100 & See Fig. 33 for test history - anchor extracted - soil displaced by anchor \\
\hline $22 \operatorname{Mar} 72$ & $11-\mathrm{B}$ & GMS & 12 & Hanover silt & $55^{\circ}$ & 100 & See Fig. 33 for test history - anchor extracted - soil displaced by anchor \\
\hline 23 Mar 72 & $12-B$ & GMS & 12 & Hanover silt & $55^{\circ}$ & 100 & See Fig. $\mathbf{3 3}$ for test history - anchor extracted - soil displaced by anchor \\
\hline $29 \operatorname{Mar} 72$ & $13-\mathrm{B}$ & $1 / 5$ & 6 & Hanover silt & $55^{\circ}$ & 45 & See Fig. 33 for test history - anchor extracted - soil displaced by anchor \\
\hline 27 Apr 72 & 14-B & $1 / 4$ & 15 & Hanover silt & $55^{\circ}$ & 100 & See Fig. 33 for test history - anchor extracted - soil displaced by anchor \\
\hline 2 May 72 & $15-\mathrm{B}$ & $\frac{14}{1 / 4}$ & 15 & Hanover silt & $55^{\circ}$ & 75 & See Fig. 33 for test history - anchor extracted - soil displaced by anchor \\
\hline 4 May 72 & $16-\mathrm{B}$ & $1 / 4$ & 15 & Hanover silt & $55^{\circ}$ & 50 & See Fig. 33 for test history - anchor extracted - soil displaced by anchor \\
\hline 5 May 72 & $17-\mathrm{B}$ & $1 / 4$ & 15 & Hanover silt & $55^{\circ}$ & 125 & See Fig. 33 for test history - anchor extracted - soil displaced by anchor \\
\hline 16 May 72 & $18-\mathrm{B}$ & $1 / 4$ & 15 & Hanover silt & $55^{\circ}$ & 125 & See Fig. 33 for test history - anchor extracted - soil displaced by anchor \\
\hline 22 May 72 & $19-\mathrm{B}$ & $1 / 4$ & 15 & Hanover silt & $55^{\circ}$ & 125 & See Fig. 33 for test history - anchor extracted - soil displaced by anchor \\
\hline 30 May 72 & $20-\mathrm{B}$ & $1 / 4$ & 15 & Hanover silt & $55^{\circ}$ & 125 & See Fig. 33 for test history - anchor extracted - soil displaced by anchor \\
\hline 5 Jun 72 & $21-B$ & $1 / 4$ & 15 & Hanover silt & $55^{\circ}$ & 175 & See Fig. 33 for test history - anchor extracted - soil displaced by anchor \\
\hline 19 Jun 72 & $22-\mathrm{B}$ & GMS & 12 & Hanover silt & $55^{\circ}$ & 75 & See Fig. 33 for test history - anchor extracted - soil displaced by anchor \\
\hline $\begin{array}{l}\text { Shank a } \\
\text { Grizzly }\end{array}$ & bec & & & d 10 & e & . & ded in $50 \mathrm{lb}$ increments each hour \\
\hline
\end{tabular}




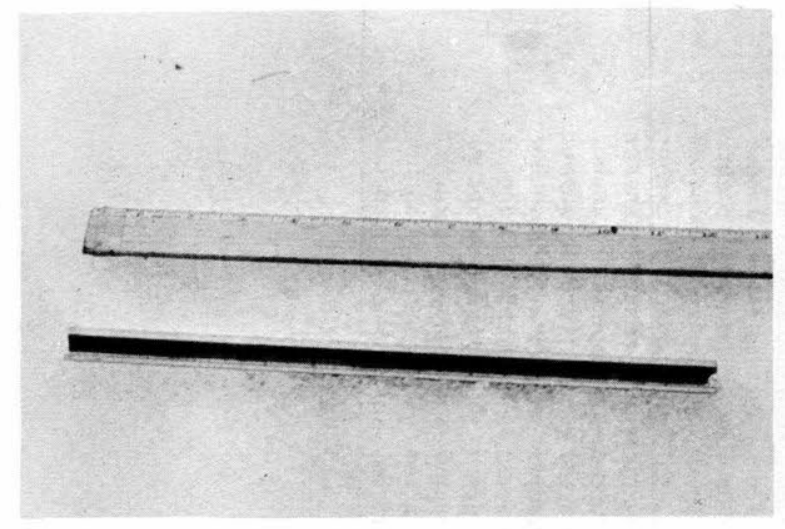

a. Horizontal view.

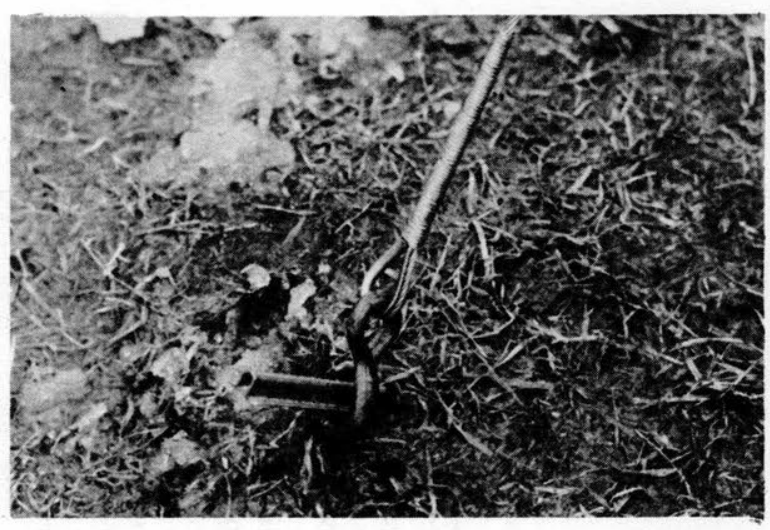

b. End view during load test.

Figure 7. Grizzly Mini Stake.

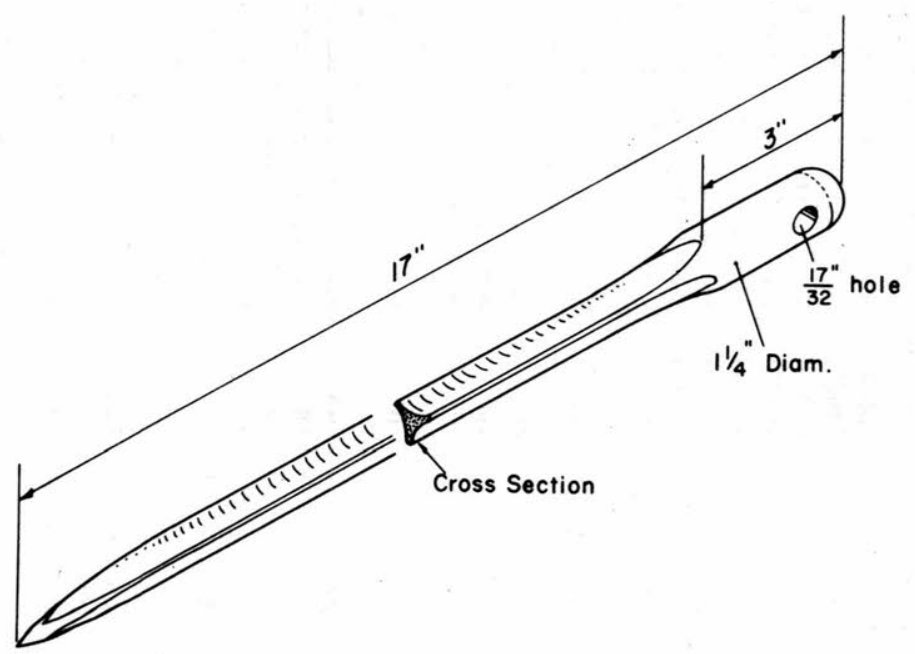

Figure 8. Dimensions of GP-112/G stake.

\section{Anchor installation}

All anchors were installed using a 2-1b ball hammer. Driving time for most of the hook anchors was always less than one minute, and more often than not less than $30 \mathrm{sec}$. The hook anchors were driven the full length of their shank following the procedure outlined by the manufacturer (Fig. 9). The GP-112/G and GM stakes were driven at an angle of $45^{\circ}$ to an embedment depth of 14 and 8 in. respectively.

\section{Test apparatus}

In 1970 a hydraulic jack was used to apply an axial load to the Anker spring arm, i.e. a horizontal load was applied to the arm. The load was measured by a Hydroscale as shown in Figure 10.

The load system used in 1971 consisted of a compressed gas pneumatic ram configured to apply a load to the hook anchor spring arm at a $45^{\circ}$ angle. Pressure sensing gages on the load apparatus were able to maintain a set load automatically over an extended period of time. The load system is shown in Figure 11 loading a $5 / 16$-in.-diameter hook anchor.

The above load system was also used during the 1972 anchor tests. However, for these tests the ram was configured to apply anchor load at an angle of $60^{\circ}$. In addition to this device, a dead weight loading system 


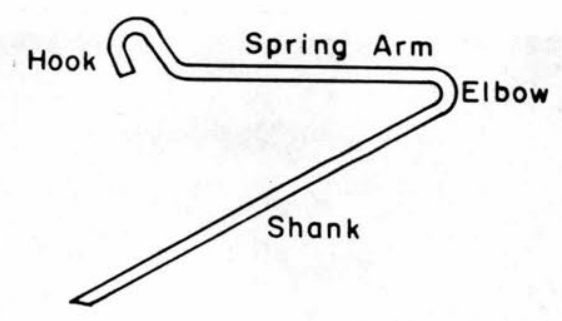

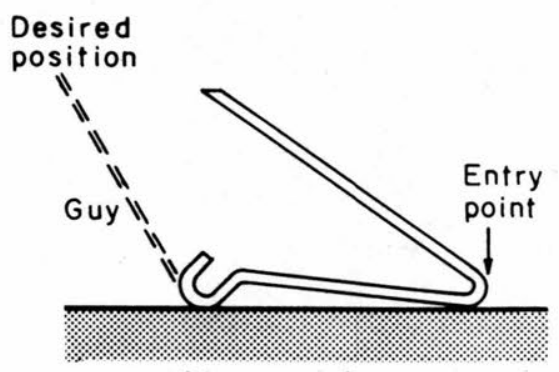

a. Using length of spring arm, measure for shank entry point as shown.

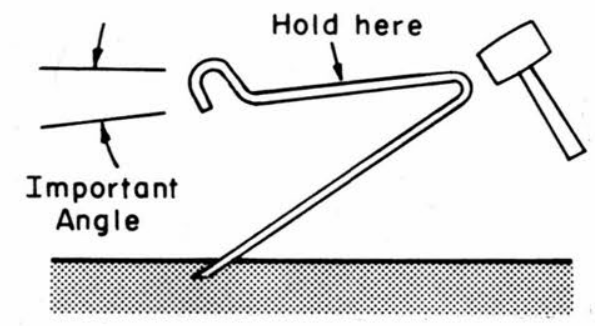

c. Move anchor over so that spring arm is at a small angle to the horizontal $\left(5^{\circ}-10^{\circ}\right.$ on grass, $2^{\circ}-4^{\circ}$ in blacktop). Drive home using firm grip on spring arm so that angle is maintained.

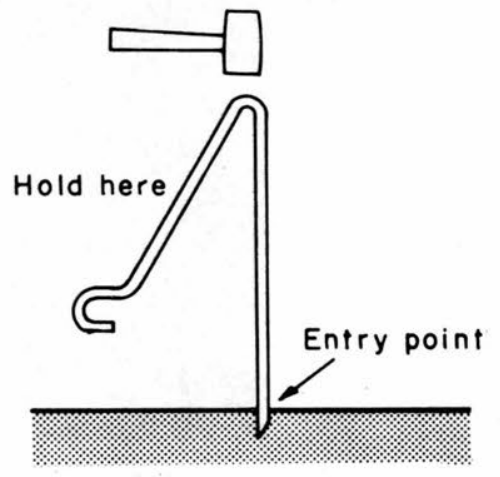

b. With shank of anchor held vertically at entry point, drive $2^{\prime \prime}$ into ground (1/2" in blacktop).

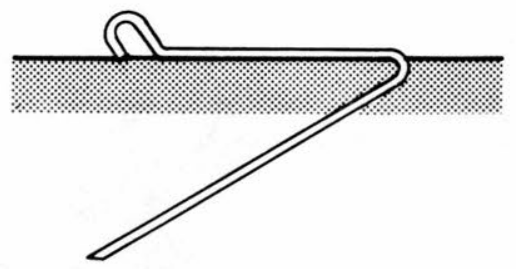

d. When driven home, the anchor should lie completely flat with the hook pressing sufficiently hard against the ground that normal guy tension will not raise it.

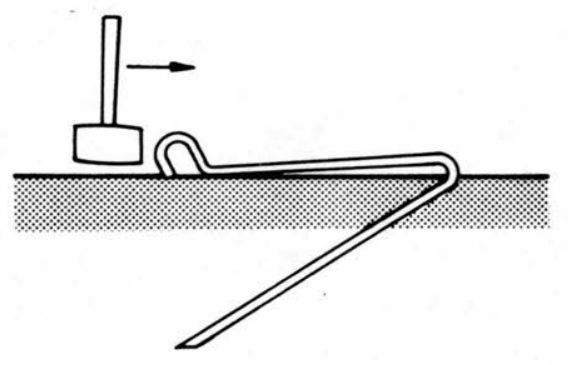

e. To remove, release guy and tap hook backward until there is sufficient room at elbow to insert finger and pull free.

Figure 9. Manufacturer's recommended procedure for driving and retrieving hook anchors. 


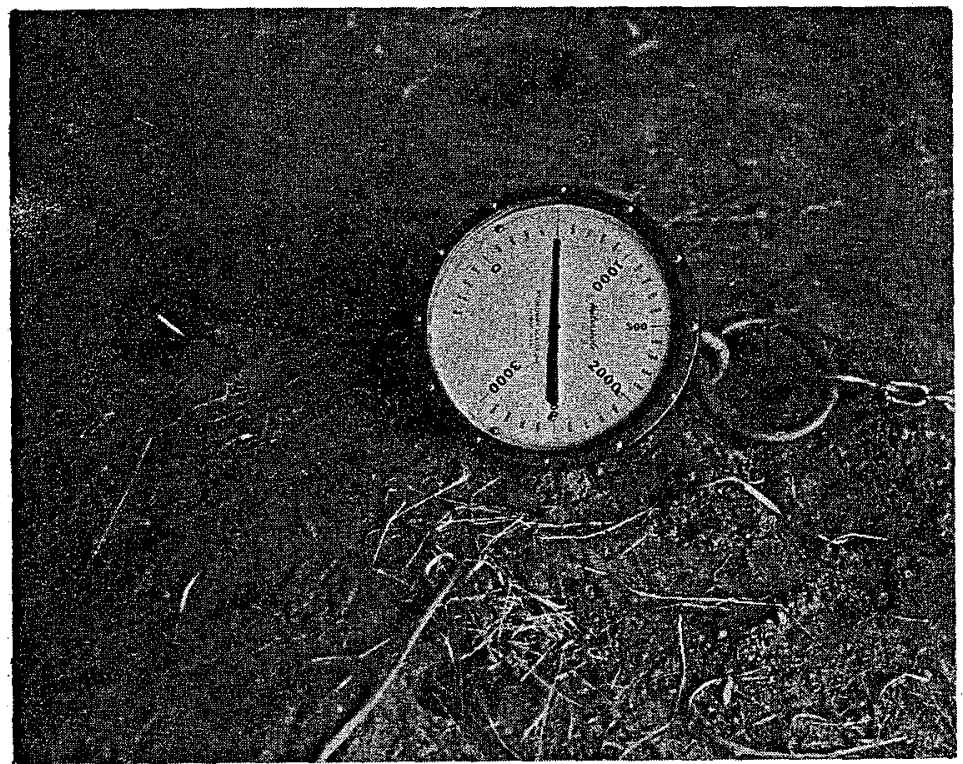

Figure 10. Loading arrangement used during the 1970 hook anchor tests in Fairbanks.

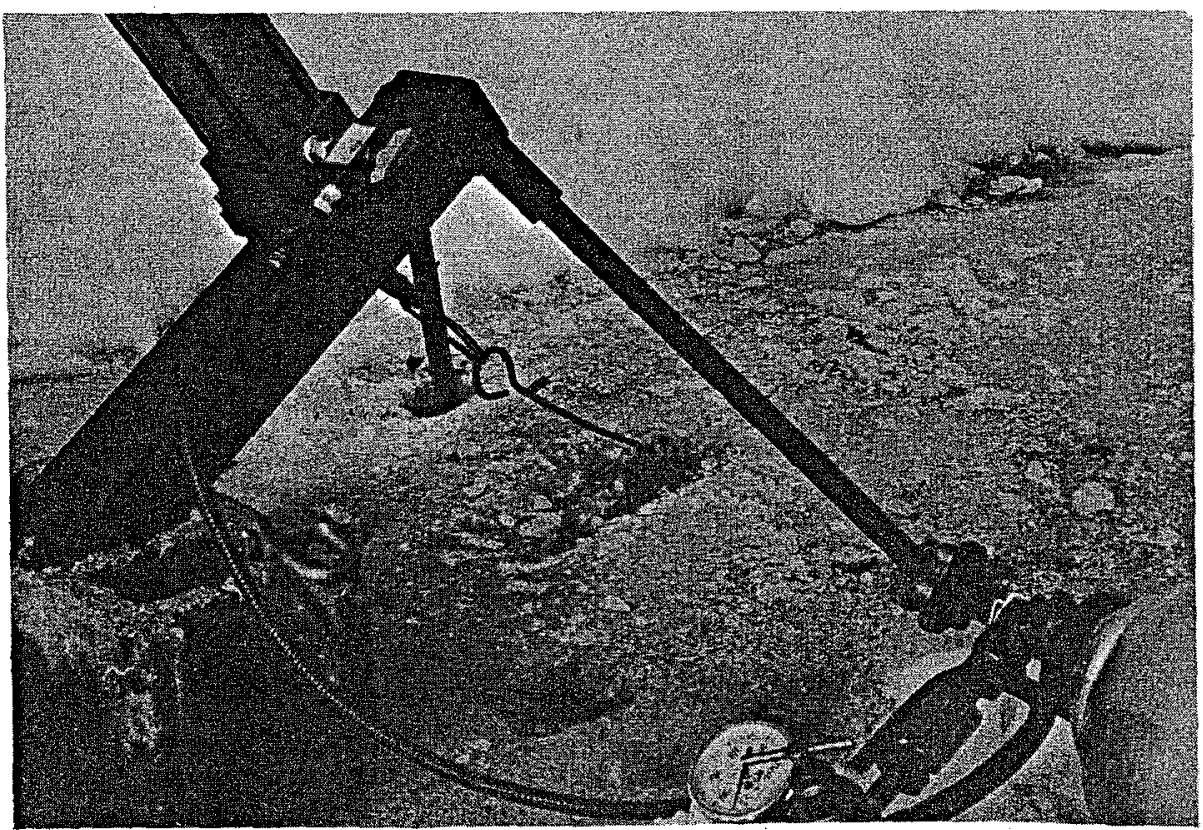

Figure 11. Pneumatic ram loading system used during the 1971 and 1972 anchor tests. 


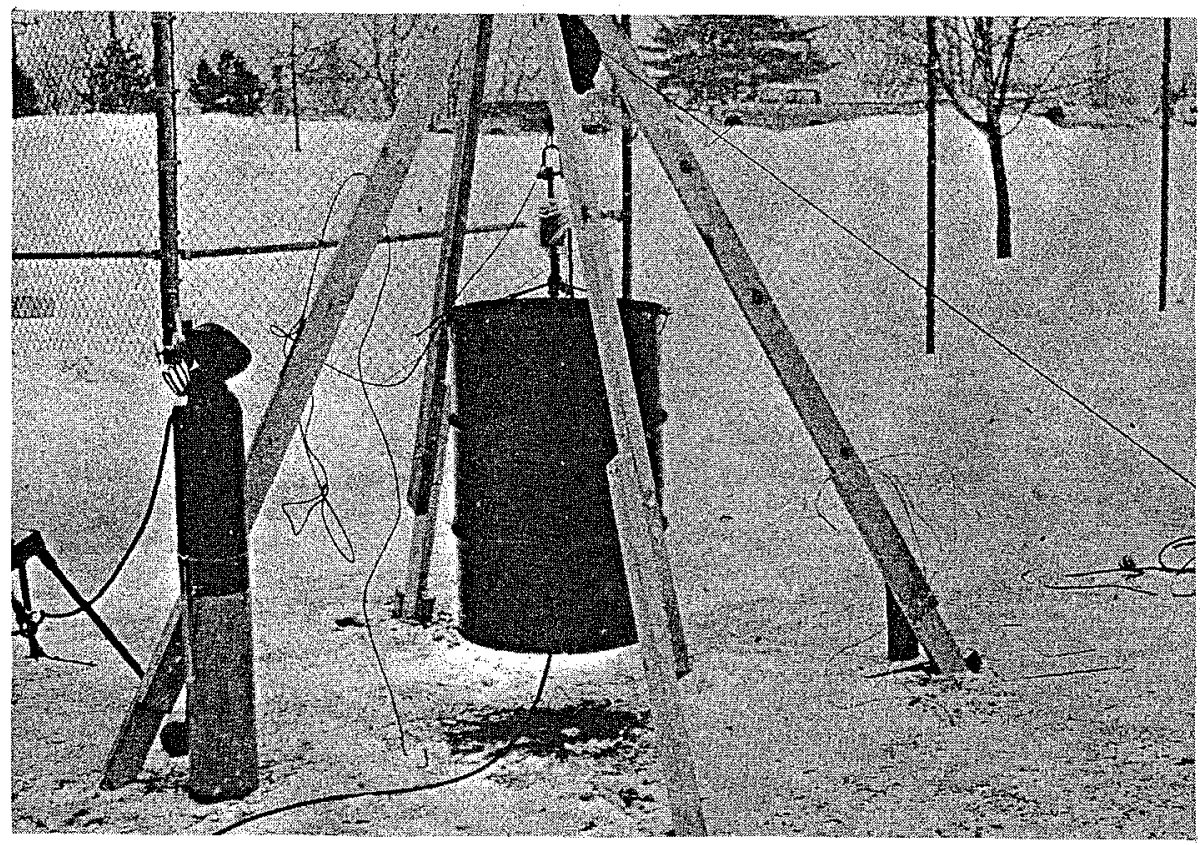

Figure 12. Dead weight loading system used to apply long term anchor loads in 1972.

was also used in 1972. This consisted of a 55 -gal. drum suspended on a steel cable. The cable passed over a support sheave, suspended as shown in Figure 12, down to the test anchor. Dead weight consisted of the barrel weight and that of the nonfreezing solution pumped into the barrel. Anchor load was determined from a load cell suspended from the cable above the barrel (see Fig. 12). The load was recorded continuously on a strip chart recorder.

Anchor deflection was measured using an engineer's tape or determined from a strip chart record of the output from a displacement transducer.

\section{Anchor tests}

The purpose of the 1970 anchor tests was to gather background information related to installation, removal and holding capacity of hook anchors in the frozen silt. Sixteen tests were conducted. All anchors were subjected to a load applied parallel to the ground.

One anchor was loaded at $1000 \mathrm{lb}$ for one hour to observe its creep. Five anchors were loaded in increments until extraction or excessive creep occurred. Each load increment was maintained for $30 \mathrm{~min}$. Ten anchors were subjected to an initial ram load of between 500 and $1000 \mathrm{lb}$.

The purpose of the latter tests was to observe load drop-off as a result of anchor creep vs time. The point at which no further load decay occurred as a result of anchor creep was noted. This load would then represent the long-term holding capacity of the anchor for the soil conditions existing at the time of the test. It was later discovered that load decay resulted not only from anchor creep but also from a loss of hydraulic pressure due to seepage of hydraulic oil past seals in the ram. These test results are therefore of little value and are not presented.

Anchor 1-H (1/2-in. diameter, 18-in. shank). Considerable resistance was experienced during the driving of this anchor. Driving time was about one minute.

A load of $1000 \mathrm{lb}$ was applied to the anchor for one hour during which its deflection was recorded (Fig. 13). It is uncertain how long the anchor could have resisted this load, as its creep rate during the last $20 \mathrm{~min}$ of the test was on the order of $1 / 4$ in. per hour. Nevertheless, it is clear from Figure 13 that the anchor was able to resist a short-term load of $1000 \mathrm{lb}$ without experiencing extraction or excessive creep. 


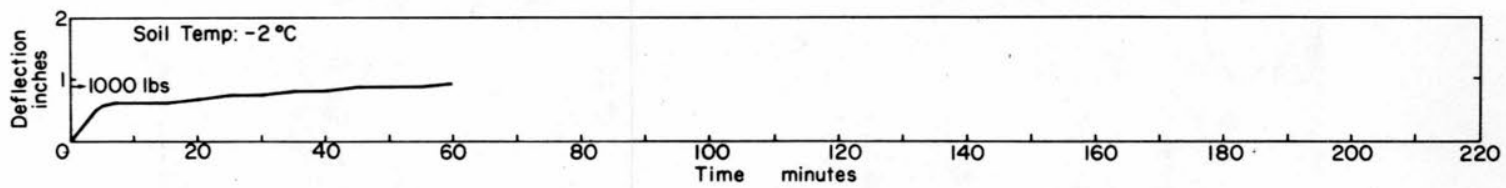

Figure 13. Load-deflection history of anchor 1-H.

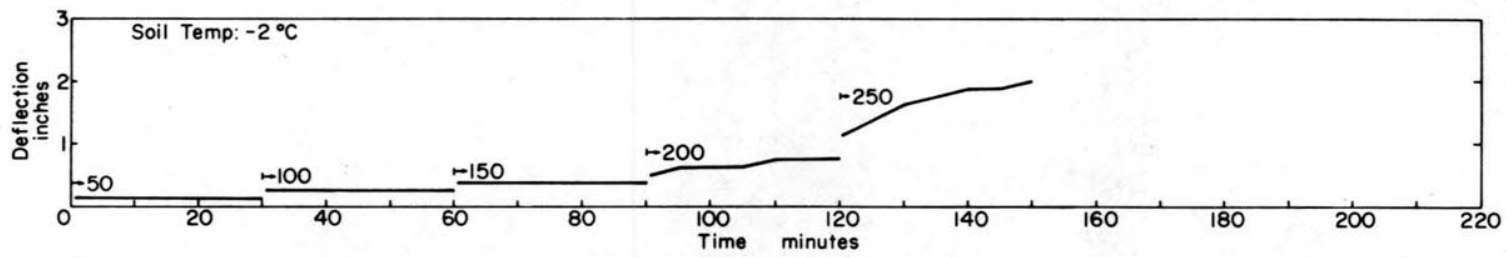

Figure 14. Load-deflection history of anchor 2-H.

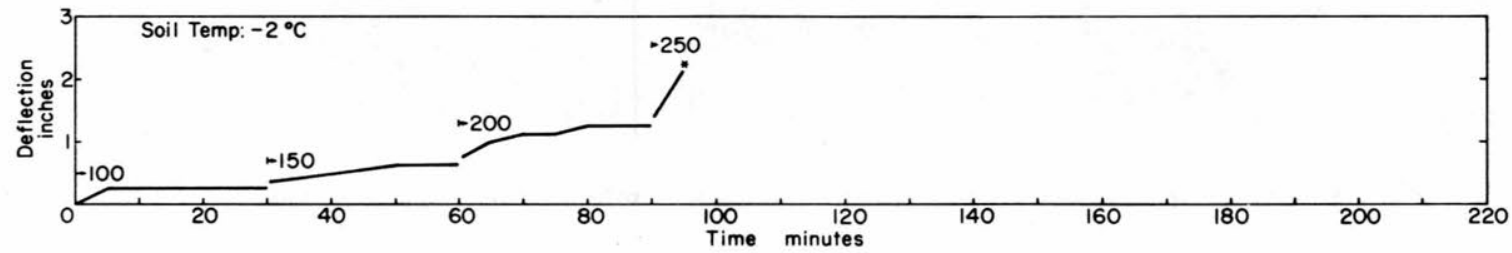

Figure 15. Load-deflection history of anchor 3-H (*anchor extracted).

The anchor was removed without great difficulty as outlined in Figure 9.

Anchor 2-H (3/16-in. diameter, 9-in. shank). The anchor was driven in less than one minute without excessive effort.

The anchor was loaded in 50-1b increments every $30 \mathrm{~min}$ to a total load of $250 \mathrm{lb}$ (see Fig. 14). At the end of the 250-lb load period the anchor had crept forward 2 in. and appeared on the threshold of being withdrawn. The test was therefore terminated.

Upon removal the anchor's included angle was found somewhat enlarged and the shank was bent where it had been pulled against the soil. Although the anchor could be straightened and reused, it is suspected that it had suffered a slight reduction in its rigidity and would not perform as well under load again.

Anchor 3-H (3/16-in. diameter, 9-in. shank). The anchor was driven with difficulty but in less than one minute.

The load deflection history for this anchor is shown in Figure 15. The anchor appeared able to restrain a load of $200 \mathrm{lb}$ but at $250 \mathrm{lb}$ the anchor was gradually withdrawn from the ground.

After extraction the anchor's included angle had greatly increased and the shank was bent. While not a photo of this anchor, an example of the deformation sustained is shown in Figure 16. Anchor 3-H was restraightened in a vice with the use of a $2-1 b$ hammer.

Anchor 4-H (3/16-in. diameter, 9-in. shank). Hard hammer blows were required to embed this anchor. It is believed that a stiffer shank would have improved the driving performance of the anchor.

The load history of the anchor is presented in Figure 17. At the end of the 150-lb load period the anchor had been withdrawn $1 \frac{1}{2}$ in. and was experiencing a creep rate on the order of $1 / 2$ in. per hour. At the end of the 200-1b load period, the anchor had been withdrawn nearly 4 in. and was being extracted at about 1 in. per hour. When $250 \mathrm{lb}$ was applied to the anchor it was quickly withdrawn. 


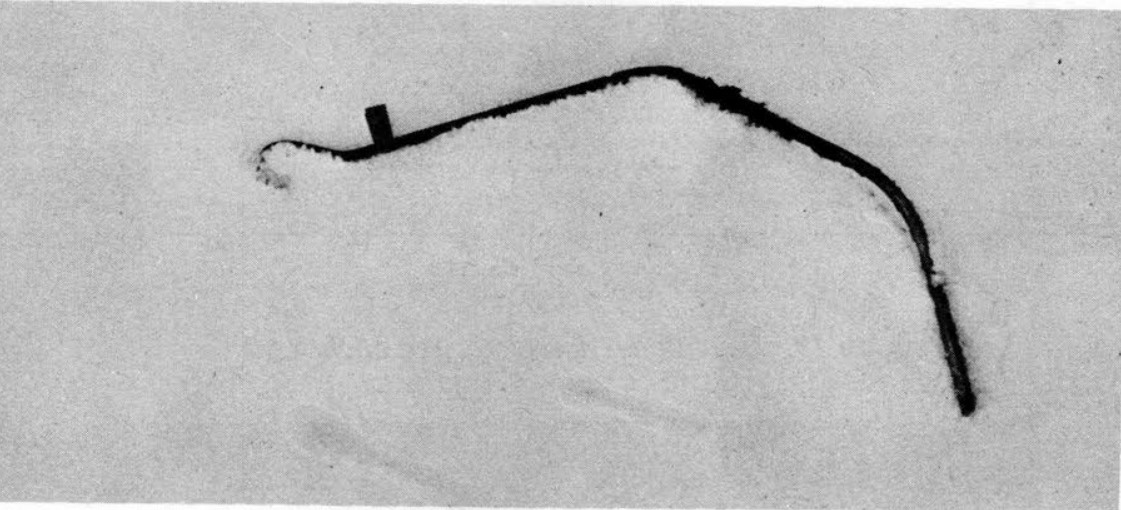

Figure 16. Typical deformation sustained by hook anchors drawn out of frozen ground.

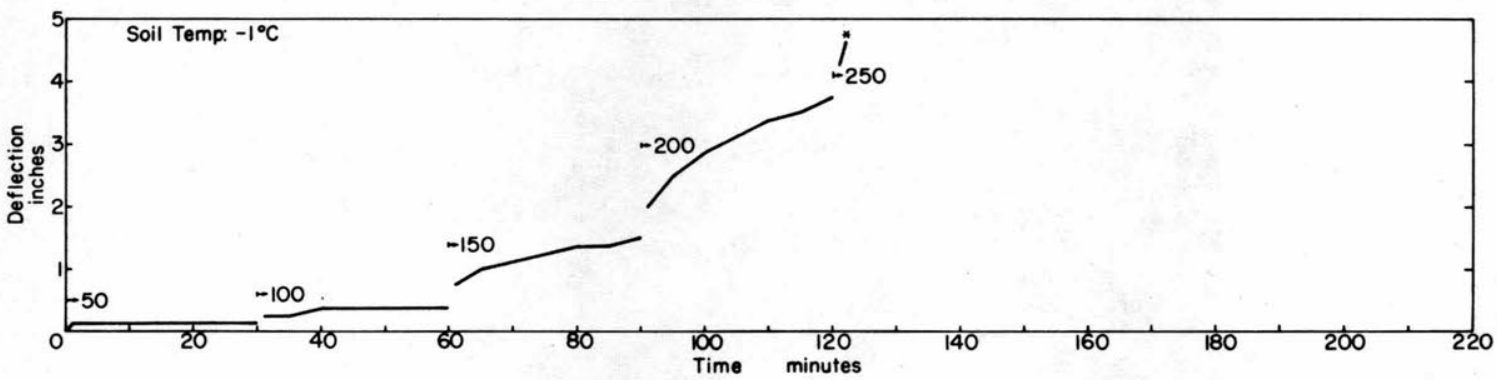

Figure 17. Load-deflection history of anchor 4-H.

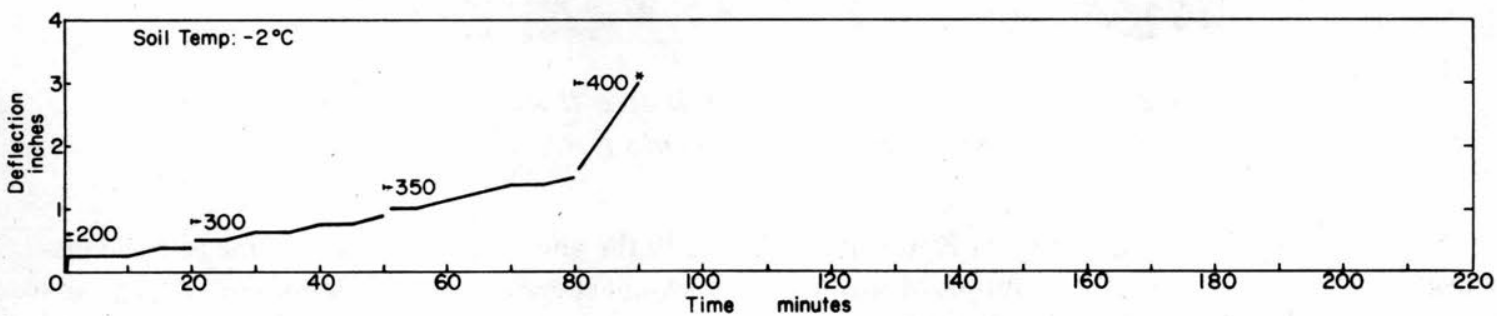

Figure 18. Load-deflection history of anchor 5-H.

The anchor had experienced structural deformation similar to that shown in Figure 16.

Anchor 5-H (3/16-in. diameter, 9-in. shank). Driving was found difficult. Shank flexing prevented efficient hammer impact energy transfer to the anchor's tip.

The load history for the anchor is shown in Figure 18. The anchor appeared able to resist transient loads (a few minutes' duration) as high as $400 \mathrm{lb}$. However, under the loads of 300 and $350 \mathrm{lb}$ the anchor was undergoing lateral displacement on the order of $1 \mathrm{in}$. per min. After $10 \mathrm{~min}$ at a load of $400 \mathrm{lb}$, the anchor was pulled out of the ground.

The anchor's shape after extraction was similar to that shown in Figure 16.

Anchor $6-H(1 / 2-i n$. diameter, 18-in. shank). Hard driving was required to embed this anchor. Driving time was in excess of one minute. 


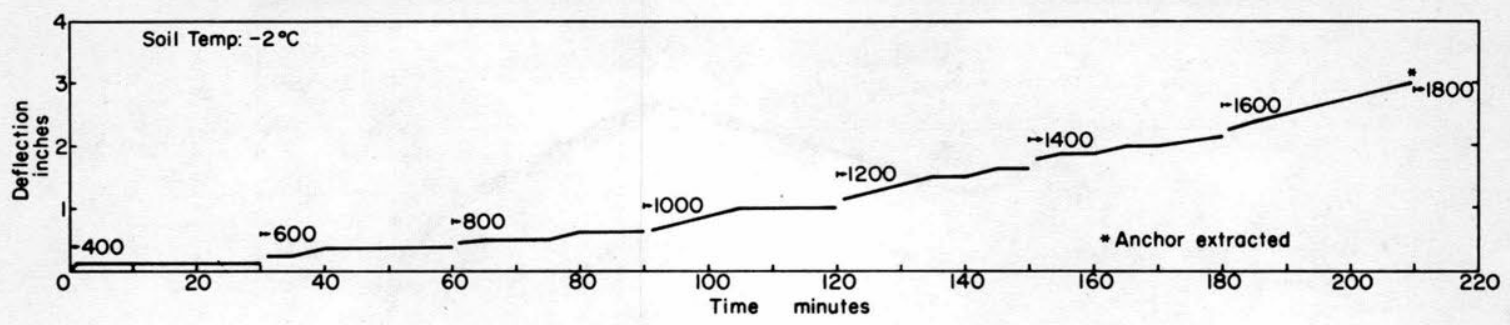

Figure 19. Load-deflection history of anchor 6-H.

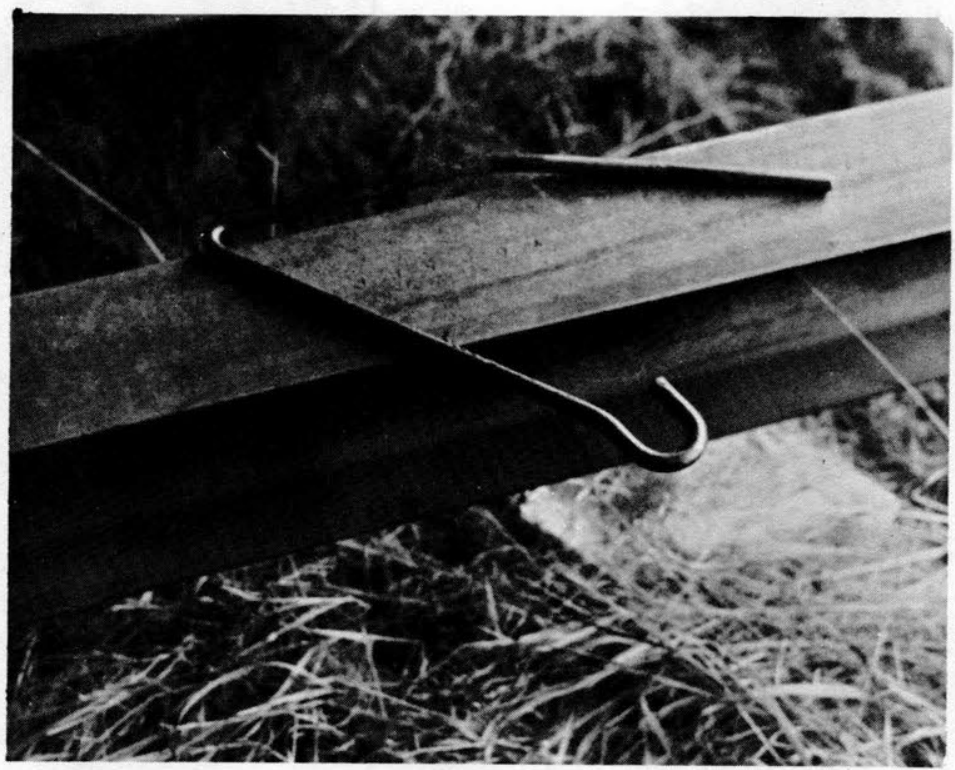

Figure 20. Configuration of anchor 6-H after it was drawn out of the frozen silt of the Fairbanks test site.

The anchor was loaded as shown in Figure 19. At $1000 \mathrm{lb}$ the anchor experienced no measurable displacement during the second 15 minutes of loading. This would suggest that the anchor could hold the load for an extended time period. At $1600 \mathrm{lb}$ the anchor was undergoing lateral displacement at $1 \frac{1}{2} \mathrm{in}$. per hour. While clearly capable of resisting this load for a short duration, the anchor would not be able to hold the load over an extended time period. The anchor was withdrawn when the load was increased to $1800 \mathrm{lb}$.

The configuration of the anchor after extraction is shown in Figure 20.

Discussion of the 1970 anchor tests. The 1970 anchor tests showed that $3 / 16^{-}$and $1 / 2$-in.-diam hook anchors could be driven into $-2^{\circ} \mathrm{C}$ silt having a frozen water content of $45 \%$ and a dry density of $66 \mathrm{lb} / \mathrm{ft}^{3}$. The driving revealed that the $3 / 16$-in.-diam shank was not stiff enough for good hammer impact energy transfer to the anchor tip. A minimum diameter of $1 / 4$ in. is suggested for a shank $9 \mathrm{in.} \mathrm{long.}$

Load tests showed that $3 / 16$-in.-diam anchors were capable of resisting transient loads of up to $250 \mathrm{lb}$ and sustained loads between 125 and $150 \mathrm{lb}$. The $1 / 2$-in.-diam anchors appear to be capable of resisting sustained loads on the order of $1000 \mathrm{lb}$ and $50 \%$ higher transient loads.

The anchors were found to be retrievable; this is a decided advantage of the anchor. 

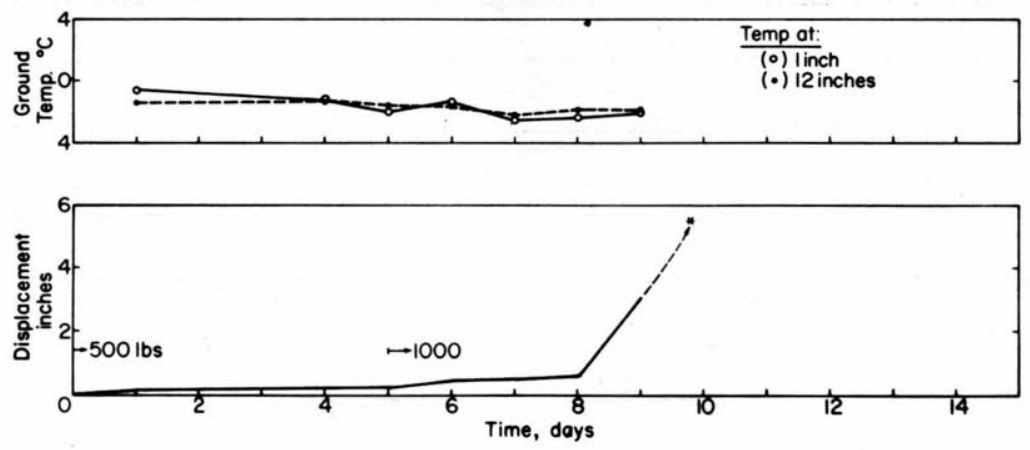

Figure 21. Test ground temperatures and load-deflection history of anchor 1-J.

\section{Anchor tests}

Five hook anchors were load tested in frozen ground and one GM stake, three GP-112/G stakes and seven hook anchors were load tested in thawed ground. The anchors were loaded in increments. The force applied was dependent upon anchor size and expected capacity. Load duration varied as a result of such factors as anchor capacity and test load remaining over a weekend. All loads were applied at an angle of $45^{\circ} \pm 5^{\circ}$.

In addition, five hook anchors were driven into frozen ground and allowed to freeze in. The relative effort required to remove them was later determined.

Anchor 1-J $(1 / 2$-in. diameter, 18-in. shank). The anchor was driven in less than one minute. Hard driving was experienced.

Anchor load history and ground temperature conditions during the test are shown in Figure 21. During the last four days of the first load increment of $500 \mathrm{lb}$, the anchor was moving slowly at $0.02 \mathrm{in}$. per day. At the next load level of $1000 \mathrm{lb}$ the anchor experienced a creep rate of $0.1 \mathrm{in}$. per day for three days followed by a sudden acceleration of over 1 in. during the fourth day and extraction on the fifth day.

The results suggest that for existing test conditions the anchor could resist a 500-lb load for an extended time period and short duration (hours) transient loads of $1000 \mathrm{lb}$.

Anchor 2-J (5/8-in. diameter, 18-in. shank). The anchor was driven in less than one minute.

Anchor load history and the ground temperature during the test are shown in Figure 22. The anchor was loaded in 500-lb increments. At a load of $1000 \mathrm{lb}$ and during the first four days at $1500 \mathrm{lb}$ the anchor was experiencing negligible creep. After the fourth day at a load of $1500 \mathrm{lb}$ the anchor's creep rate increased to $0.05 \mathrm{in}$. per day for the next two days. The following day (the seventh day at $1500 \mathrm{lb}$ ) the anchor suddenly crept out of the ground. The increase in the anchor's movement on the fifth day and its eventual failure on the seventh is related to an increase in ground temperature which occurred at the time (see Fig. 22).

For the existing test conditions the anchor appeared to be capable of sustaining a load of $1000 \mathrm{lb}$ and an intermittent load (one or two days) of up to $1500 \mathrm{lb}$.

Anchor 3-J (3/8-in. diameter, 12-in. shank). The anchor was driven in less than one minute.

Soil temperature during the test averaged $-0.5^{\circ} \mathrm{C}$. The anchor was loaded to $250 \mathrm{lb}$. At the end of the first day the anchor had moved approximately $1 / 2$ in. During the second load day the anchor snapped in two at the elbow.

Anchor 4-J (3/8-in. diameter, 12-in. shank). Driving of the anchor took less than one minute.

Soil temperature during the test was approximately $-1{ }^{\circ} \mathrm{C}$. At the end of three days the anchor had moved less than $0.1 \mathrm{in.}$ On the fourth day of loading the anchor broke in two at the elbow. 

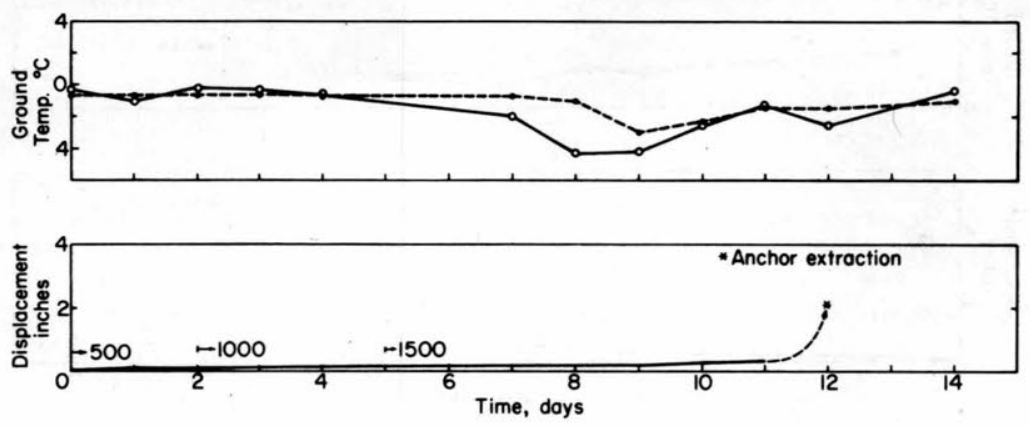

Figure 22. Test ground temperatures and load-deflection history of anchor 2-J.

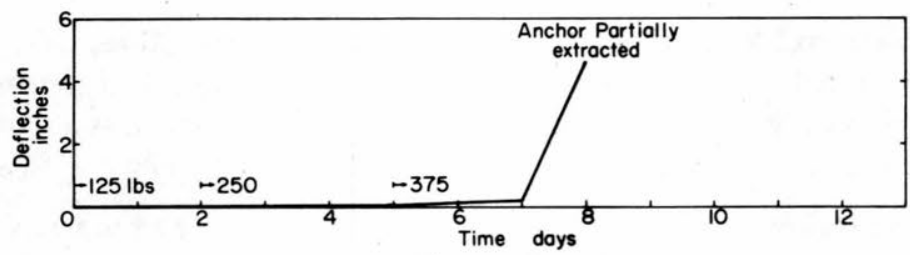

Figure 23. Load-deflection history of anchor 6-J.

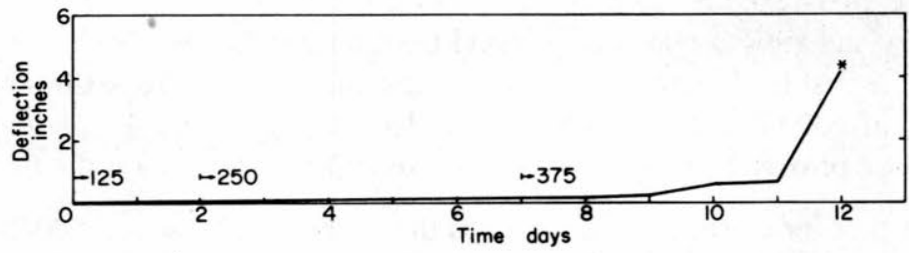

Figure 24. Load-deflection history of anchor 7-J.

Anchor 5-J (5/8-in. diameter, 18-in. shank). The anchor was driven in place in less than one minute.

Soil temperature during the test was approximately $-0.5^{\circ} \mathrm{C}$. The anchor appeared capable of holding a load of $500 \mathrm{lb}$ without excessive creep ( $0.05 \mathrm{in}$. per day). When loaded from $500 \mathrm{lb}$ to $1000 \mathrm{lb}$ the anchor was quickly pulled from the ground.

Anchor 6-J (5/8-in. diameter, 18-in. shank). Anchor installation time was less than $30 \mathrm{sec}$ into the thawed ground.

The anchor's load history is presented in Figure 23. After two days at a load of $125 \mathrm{lb}$ and three days at a load of $250 \mathrm{lb}$ the anchor experienced virtually no movement. The first two days at a load of $375 \mathrm{lb}$ resulted in a deflection of $0.15 \mathrm{in}$. On the third day at this load the soil failed and the anchor was extracted as far as the ram would travel.

It may be summarized from the test data that the anchor could hold the second load increment of $250 \mathrm{lb}$ and transient loads as high as $375 \mathrm{lb}$.

Anchor $7-J(5 / 8$-in. diameter, 18-in. shank). The anchor was driven in less than $30 \mathrm{sec}$ into the unfrozen ground.

The load test data are presented in Figure 24. The results indicate that the anchor could hold a load of $250 \mathrm{lb}$ in the unfrozen silt and a temporary load (several days) on the order of $350 \mathrm{lb}$. 


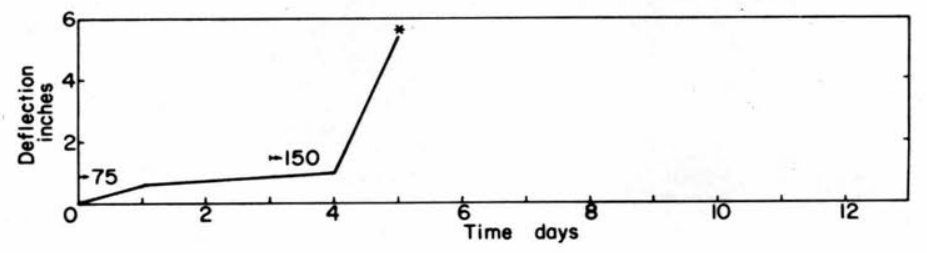

Figure 25. Load-deflection history of anchor 9-J.

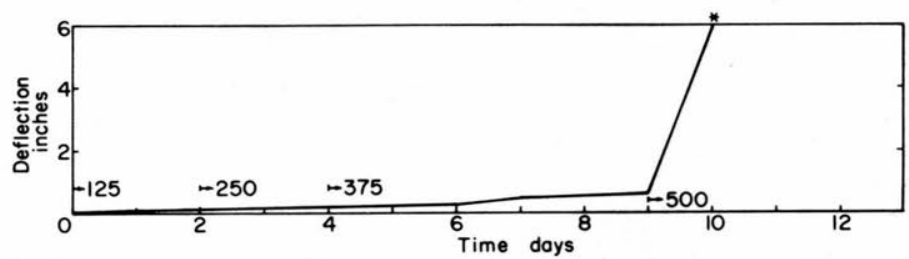

Figure 26. Load-deflection history of anchor 11-J.

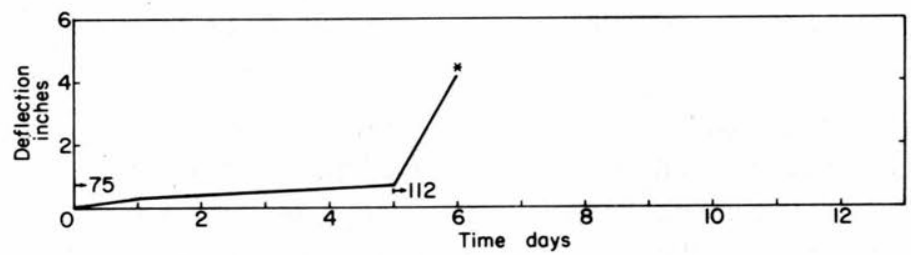

Figure 27. Load-deflection history of anchor 12-J.

Anchor 8-J $(3 / 8$-in. diameter, 12-in. shank). The anchor was driven in less than $30 \mathrm{sec}$.

A load of $150 \mathrm{lb}$ was applied to the anchor. The soil, unable to resist the anchor load, failed and the anchor was pulled out of its embedment.

Anchor 9-J $(3 / 8$-in. diameter, 12-in. shank). Driving time for the anchor was less than $30 \mathrm{sec}$.

The anchor's load history is shown in Figure 25. At the end of the third day at a load of $75 \mathrm{lb}$, the anchor was creeping at approximately $0.1 \mathrm{in}$. per day. The anchor failed on the second day of the 150 -lb loading.

Anchor $10-\mathrm{J}(3 / 8$-in. diameter, 12-in. shank). Driving of the anchor took less than $30 \mathrm{sec}$.

When loaded to $75 \mathrm{lb}$ the anchor snapped off at the elbow.

Anchor 11-J (5/8-in. diameter, 18-in. shank). The anchor was driven in less than $30 \mathrm{sec}$.

The anchor's deflection vs load is shown in Figure 26. At a load of $375 \mathrm{lb}$ the anchor was creeping at 0.05 in. per day. When the load was raised to $500 \mathrm{lb}$ the anchor cut into the soil and eventually failed by being pulled out of the ground. The anchor appeared to have a sustained load capacity of $250 \mathrm{lb}$, a short term capacity (several weeks) of 375 and intermittent holding capacity (tens of minutes) of $500 \mathrm{lb}$.

Anchor 12-J (GM stake, embedded $10 \mathrm{in}$.). The stake was driven in less than $30 \mathrm{sec}$.

The deflection vs load history for the anchor is presented in Figure 27. The anchor was capable of resisting a load of $75 \mathrm{lb}$ at a creep rate of $0.1 \mathrm{in}$. per day. During the first day at a load of $112 \mathrm{lb}$ the soil failed, the anchor shank bent and the anchor was extracted. The anchor appears capable of resisting a sustained load of $50 \mathrm{lb}$ and a short term load of $75 \mathrm{lb}$.

Anchor 13-J (GP-112/G stake, embedded $14 \mathrm{in.})$. Less than $30 \mathrm{sec}$ was required to drive the stake. 


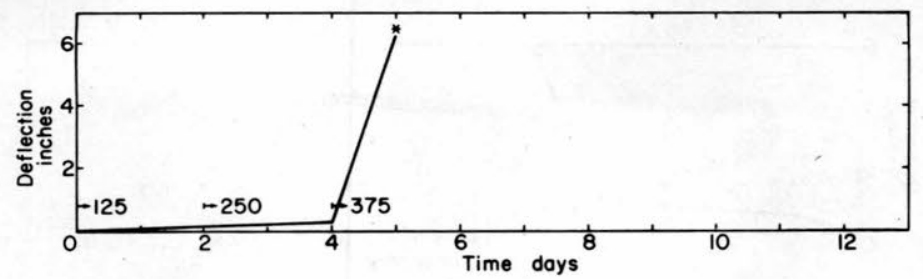

Figure 28. Load-deflection history of anchor 13-J.

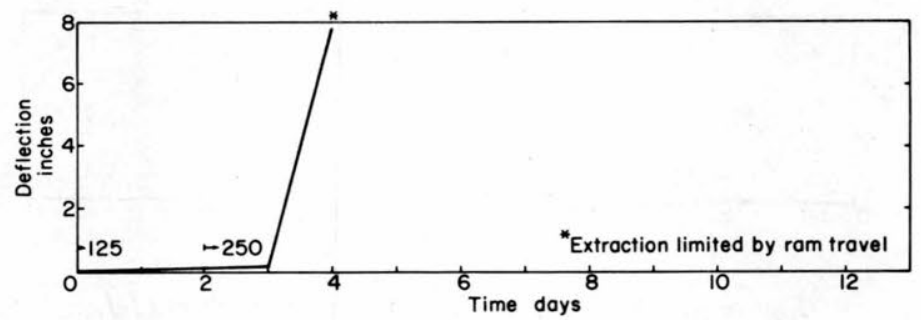

Figure 29. Load-deflection history of anchor 14-J.

The stake's deflection vs load is given in Figure 28. At a load of $250 \mathrm{lb}$ the stake was creeping at less than $0.1 \mathrm{in}$. per day. On the first day at a load of $375 \mathrm{lb}$ the stake failed. This low failure load was surprising considering the surface area of this anchor compared to a $5 / 8$-in.-diam hook anchor which resisted a higher load before being extracted. The stake appeared to be able to restrain a load of $250 \mathrm{lb}$.

Anchor 14-J (GP-112/G stake embedded $14 \mathrm{in.}$ ). The stake was driven in less than $30 \mathrm{sec}$.

The deflection vs load history for the stake is given in Figure 29. At a load of $125 \mathrm{lb}$ the stake was creeping at approximately $0.05 \mathrm{in}$. per day. During the second day at a load of $250 \mathrm{lb}$ the soil restraining the anchor failed and the anchor was extracted. Once again the anchor failed at a surprisingly low load.

Anchor 15-J (GP-112/G stake, embedded $14 \mathrm{in}$.). The stake was driven in less than $30 \mathrm{sec}$.

The stake was loaded in 100-1b increments to $300 \mathrm{lb}$. Stake creep at the load of $200 \mathrm{lb}$ was approximately 0.05 in. per day. During the first day at the load of $300 \mathrm{lb}$ the soil in front of the anchor crept excessively and the anchor was withdrawn.

Extraction of hook anchors. On 15 March five hook anchors were driven into the frozen silt at the CRREL test site. One week later the anchors were removed as follows. The anchors were struck on the front of the hook (see Fig. 9) with hard blows from a 2-lb hammer. At the same time the anchor arm was pushed from side to side to the extent ground clearance would allow. When the shank began to work free and ground clearance allowed, the spring arm at the elbow was pulled by hand in an upward direction parallel to the axis of the shank. At the same time the anchor arm was rotated back and forth. The effort required to remove the anchors was not an easy one, but the anchors could be and were extracted. This retrieval capability is of major importance to troops moving about in the field during the winter.

Discussion of 1971 anchor tests. During the winter tests, it was again shown that hook anchors could be driven into silt at $-2^{\circ}$ to $-3^{\circ} \mathrm{C}$ having a dry density of $60 \mathrm{lb} / \mathrm{ft}^{3}$ and a moisture content on the order of $29 \%$. It was noted that the angle at the tip of the shank hampered the start of anchor penetration in frozen ground. The slope of the point face allowed the shank tip to skip across the ground without penetrating when step C in Figure 9.was attempted. To overcome this problem it is necessary that the shank tip be cut so that the point, instead of being on the inside of the shank as shown in Figure 9, would be reversed to the outside. 


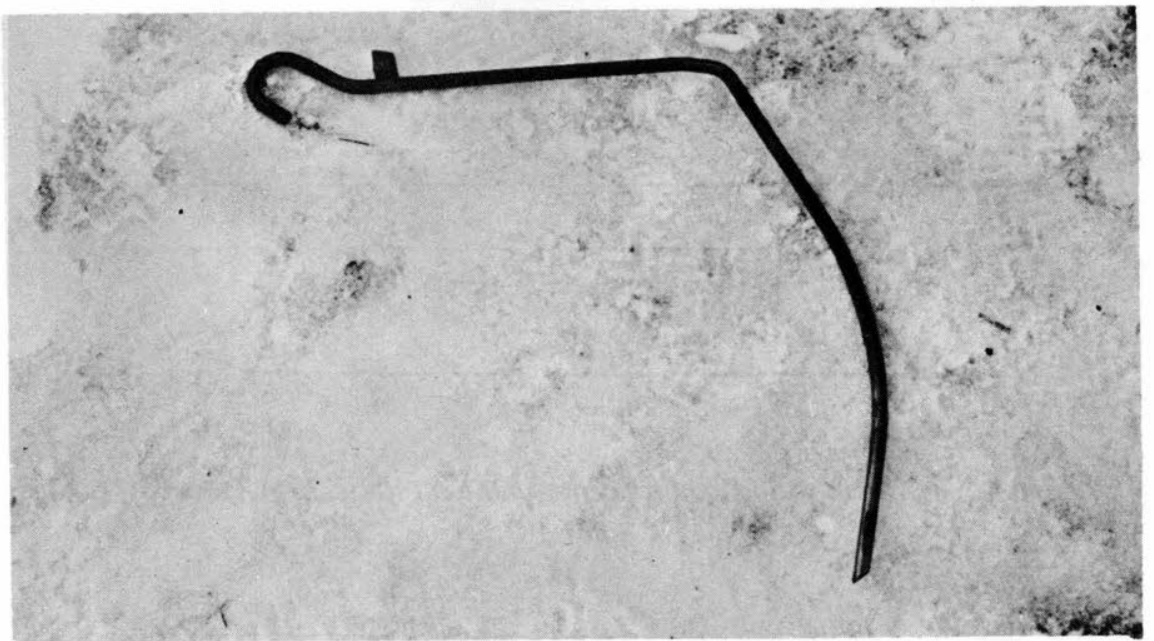

Figure 30. Post test configuration of an anchor with its included angle increased beyond $90^{\circ}$ as a result of being drawn out of its frozen ground embedment.

When hook anchors were being driven into frozen ground the driving resistance was often high and required numerous hard blows with the 2-1b hammer. The elbows of some of these anchors became slightly peened and suffered stress weakening. As a result a number of these anchors snapped off at the elbow when the anchor was subjected to relatively light loading. It is therefore assumed that the use of existing commercial hook anchors in hard frozen soil will result in a gradual loss of anchors due to breakage.

The frozen and unfrozen ground load tests showed that for their size, hook anchors are capable of resisting relatively high transient and sustained loads. The load comparison between the $5 / 8$-in.-diam hook anchor driven 18 in. and the GP-112/G stake driven 14 in. shows that the lighter and less expensive hook anchor outperformed the stake in unfrozen ground. It was observed that the holding capacity of hook anchors in frozen soil at $-1^{\circ}$ to $-2^{\circ} \mathrm{C}$ was two to three times their capacity in unfrozen ground. This shows the enormous effect soil moisture freezing has on the shear strength of the soil.

The hook anchors tested in frozen ground did not escape load extraction unharmed. Indeed, almost all anchors bent at the elbow. The included angle would at times increase to over $90^{\circ}$ and the shanks of many anchors became curved as a result of being drawn out of the soil. Figure 30 shows an anchor whose included angle has been enlarged beyond $90^{\circ}$ and whose shank has been bent.

\section{Anchor tests}

In 197227 anchors were load tested in frozen ground and nine were tested in unfrozen ground. All but four tests were made on hook anchors (the four non-hook anchors tested were GM stakes). These anchors were $1 / 8,3 / 16,1 / 4$ and $5 / 16$ in. in diameter. They were therefore smaller in diameter than the hook anchors tested in 1971. Because of their size, these anchors would appear to be more practical to use with one- or two-man tents than the larger hook anchors previously tested.

All loads were applied in increments at an angle of $55^{\circ} \pm 5^{\circ}$. Fourteen tests were short term, i.e. the anchors were loaded to failure in 50-lb increments applied at one-hour intervals. These tests are denoted by the letter $\mathrm{J}$ after the anchor test number. The incremental loads applied to the remaining 12 anchors were maintained for at least two days. These tests are denoted by the letter B after the anchor test number.

Anchor 1-B (5/16-in. diameter, 12-in. shank). The load history for the anchor is presented in Figure 31. The results indicate that the anchor experienced very little movement at the load of $200 \mathrm{lb}$ but failed during the second day at the load of $250 \mathrm{lb}$. 

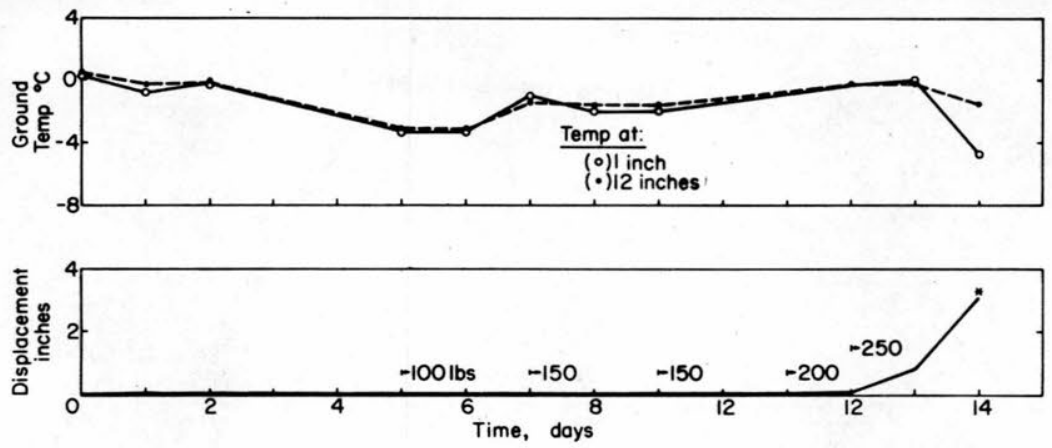

Figure 31. Test ground temperatures and load-deflection history of an. chor 1-B.
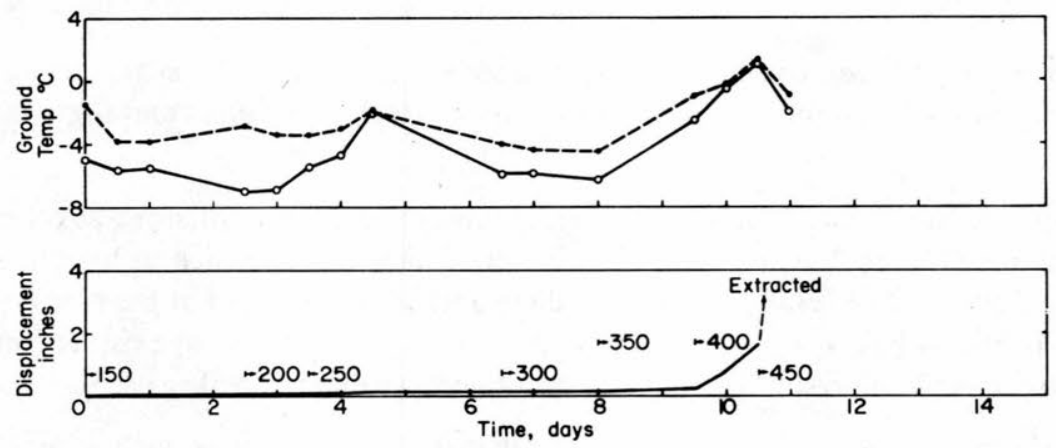

Figure 32. Test ground temperatures and load-deflection history of anchor 2-B.

Anchor 2-B (3/16-in. diameter, 9-in. shank). The anchor's deflection vs load is shown in Figure 32. At a load of $350 \mathrm{lb}$ the anchor was moving at approximately $0.3 \mathrm{in}$. per day. When loaded to $400 \mathrm{lb}$ for two days the anchor's creep accelerated to nearly $3 / 4$ in. per day, giving evidence that failure would soon occur under the rapidly rising soil temperatures. When the load was raised to $450 \mathrm{lb}$, the anchor crept out of the soil within a few hours.

Anchor 3-B (3/16-in. diameter, 9-in. shank). The anchor was extracted from the ground within 12 hours at the initial load of $100 \mathrm{lb}$.

Anchor 4-B (3/16-in. diameter, 9-in. shank). The anchor was loaded in 100-lb increments every two days. At the load of $200 \mathrm{lb}$ the creep was nearly zero. Anchor movement at the load of $300 \mathrm{lb}$ was $0.2 \mathrm{in}$. per day. After two days at the load of $400 \mathrm{lb}$ the anchor was slowly withdrawn from the frozen ground.

Anchor 5-B (5/16-in. diameter, 12-in. shank). The deflection vs load history for the anchor is given in Figure 33. The anchor experienced no movement for the two days it was loaded at $250 \mathrm{lb}$. However, the soil temperature was decreasing during this time and was therefore more resistant to displacement. At the load of $350 \mathrm{lb}$ the anchor began to creep at $0.1 \mathrm{in}$. per day. This movement is attributed to both the higher anchor-soil stress level at this load as well as to the rapidly increasing ground temperatures shown in Figure 33. After two days at $450 \mathrm{lb}$, anchor movement increased to approximately $0.4 \mathrm{in}$. per day. At the next load level of $550 \mathrm{lb}$ the anchor snapped off at the elbow.

Anchor 6-B (3/16-in. diameter, 9-in. shank). The anchor was extracted in less than 24 hours at an initial load of $100 \mathrm{lb}$. Soil temperature averaged $-0.5^{\circ} \mathrm{C}$ during the test. 

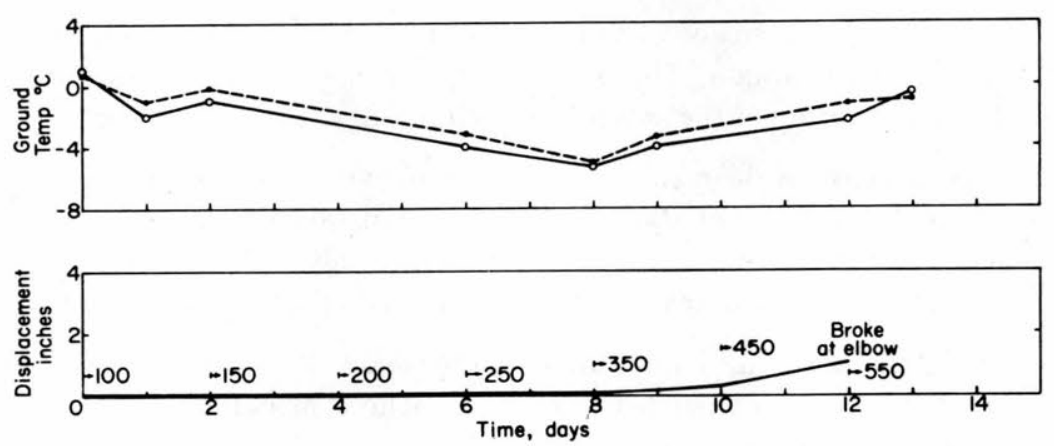

Figure 33. Test ground temperatures and load-deflection history of anchor 5-B.
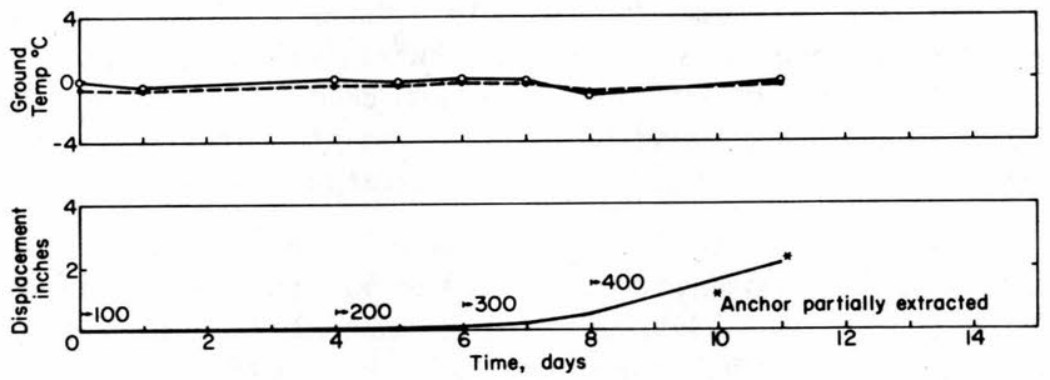

Figure 34. Test ground temperatures and load-deflection history of anchor $7-B$.

Anchor 7-B (1/4-in. diameter, 15-in. shank). The load history of the anchor is presented in Figure 34. Ground temperatures during the test were for the most part higher than $-0.5^{\circ} \mathrm{C}$. Under the $300-1 b$ loading the anchor was experiencing accelerated creep. At the end of the third day at the load of $400 \mathrm{lb}$ the anchor would have been completely extracted if the travel of the load system had been greater. In any event the anchor failed at this load.

Anchor 8-B (3/16-in. diameter, 9-in. shank). Soil temperature during the test averaged $-1{ }^{\circ} \mathrm{C}$. The anchor was loaded for two days at $50 \mathrm{lb}$ without experiencing movement. During the first day at $100 \mathrm{lb}$ the anchor remained immobile. However, during the second load day the soil gave way and the anchor was extracted.

Anchor 9-B (1/8-in. diameter, 6-in. shank). The anchor was immediately pulled from the ground at a load of $45 \mathrm{lb}$, the lowest load that could be applied with the load apparatus.

Anchors 10 through 12-B, GM stakes, embedded $10 \mathrm{in}$. The anchors resisted a load of $50 \mathrm{lb}$ without excessive movement. At a load of $100 \mathrm{lb}$ all the anchors were quickly extracted from the ground.

Anchor 13-B (1/8-in. diameter, 6-in. shank). The anchor was quickly extracted from the ground at the load of $45 \mathrm{lb}$.

Anchors 14-B through 21-B (1/4-in. diameter, 15-in. shank). These anchors were loaded every 2 days. The first load increment of $50 \mathrm{lb}$ was followed by successive $25-\mathrm{lb}$ increments. The anchors failed at the following load levels: $100,75,50,125,125,125,125,175$ and $75 \mathrm{lb}$ or at an average load of $110 \mathrm{lb}$. The ground was unfrozen during these tests. The anchors appeared to be able to resist a long term load on the order of one quarter to one third less than their failure load. 
Anchors 16-J through 29-J. These hook anchors, loaded hourly in 50-lb increments, were tested during January and February in frozen ground. The test date, anchor size and failure load for each anchor are given in Table II. The temperature of the ground for each test day is given in Table I.

The short term load capacity of these anchors may be summarized as follows. All four $1 / 4$-in.-diam anchors with 15 -in.-long shanks failed at $400 \mathrm{lb}$. Three $3 / 16$-in.-diam anchors with 9 -in. shanks failed at an average load of $130 \mathrm{lb}$. The five $5 / 16$-in.-diam anchors with 12 -in. shanks failed at an average load of $460 \mathrm{lb}$ while the three same size diameter anchors with 16-in. shanks all failed at $500 \mathrm{lb}$.

Only anchor $23-\mathrm{J}(1 / 4$ in. diam) failed structurally at the elbow. All other anchors failed by being drawn out of the ground. In the process of being extracted each anchor's included angle increased as a result of bending at the elbow and the shank became curved.

Discussions of 1972 anchor tests. As would be expected the tests showed that increasing the diameter of a hook anchor or increasing its shank length increased the holding capacity. For example, increasing the diameter from $1 / 4$ in. to $5 / 16$ in. increased the capacity of the anchor by $25 \%$. Similarly, when the shank length of the $5 / 16$-in.-diam anchor increased from 12 to 16 in. the load capacity increased approximately $10 \%$. Increasing the diameter has an apparent larger effect than increasing the shank length, i.e. embedment depth. The reason for this is undoubtedly twofold. First, the increased width of the anchor mobilizes a larger mass of soil into resisting anchor load, and second, the larger cross section stiffens the anchor, allowing for better load transfer down the anchor shank where the soil is more resistant to deformation.

Anchors tested in frozen ground again showed markedly higher holding capacity than similar anchors tested in unfrozen ground. This is typified by the $1 / 4$-in.-diam hook anchors $14-\mathrm{B}$ through 21 -B load tested in unfrozen ground and the $1 / 4$-in.-diam hook anchors 16 -J through 29 -J load tested in frozen ground. The anchors tested in unfrozen ground failed at an average load of $110 \mathrm{lb}$ while those tested in frozen ground failed at $400 \mathrm{lb}$. It should be remembered, however, that the anchors tested in unfrozen ground were loaded in 25 -lb increments every two days while those tested in frozen ground were loaded hourly in 50-lb increments. This difference in load application and duration undoubtedly had a great effect on the results too.

The load-deflection curves presented seem to indicate that hook anchors are capable of resisting long term loads on the order of two thirds of their failure load, provided the state of the soil remains unchanged. It was also observed that at two thirds the failure load, anchor shanks did not become permanently bent nor did the included angle become permanently enlarged.

A pictorial overview showing the configuration of a number of the 1972 anchors during and after testing is presented in Figures 35-39. The extreme bending of the hook anchors at the elbow when these anchors are subjected to moderate to high load is clearly shown in Figure 35. Because the anchor acts as a spring it can be expected that transient wind loads upon a guyed shelter will be gradually soaked up by arm flexure. This should reduce the stress at the guy-shelter connection and thus reduce the chance of the shelter tearing. Soil deformation and anchor configuration at the termination of load testing of hook anchors in frozen ground is shown in Figure 36. The anchors shown were only partially extracted at cessation of loading. Typical shapes of hook anchors loaded to failure, i.e. extracted, are shown in Figure 37. The anchor's included angle is shown to have increased to as much as $130^{\circ}$ as a result of high loading. The shanks on two of the anchors shown are also bent. This occurred when the anchors were drawn out over the lip of the hole in which anchors were embedded. Two examples of hook anchors which failed structurally at the elbow are shown in Figure 38. The cause of failure is believed to be related to low temperature brittleness and deformation at the elbow as a result of hammer impact. The use of hook anchors in cold climates, where hard driving in frozen ground can be expected, may therefore result in a loss of anchors due to structural failure at the elbow when the anchors are subjected to moderately high loads. Further testing is required to verify if this will indeed occur and at what load level. The shape taken by two of the GM stakes when loaded to failure is shown in Figure 39. As can be seen the anchors were severely deformed. The anchors could not be straightened for reuse. 


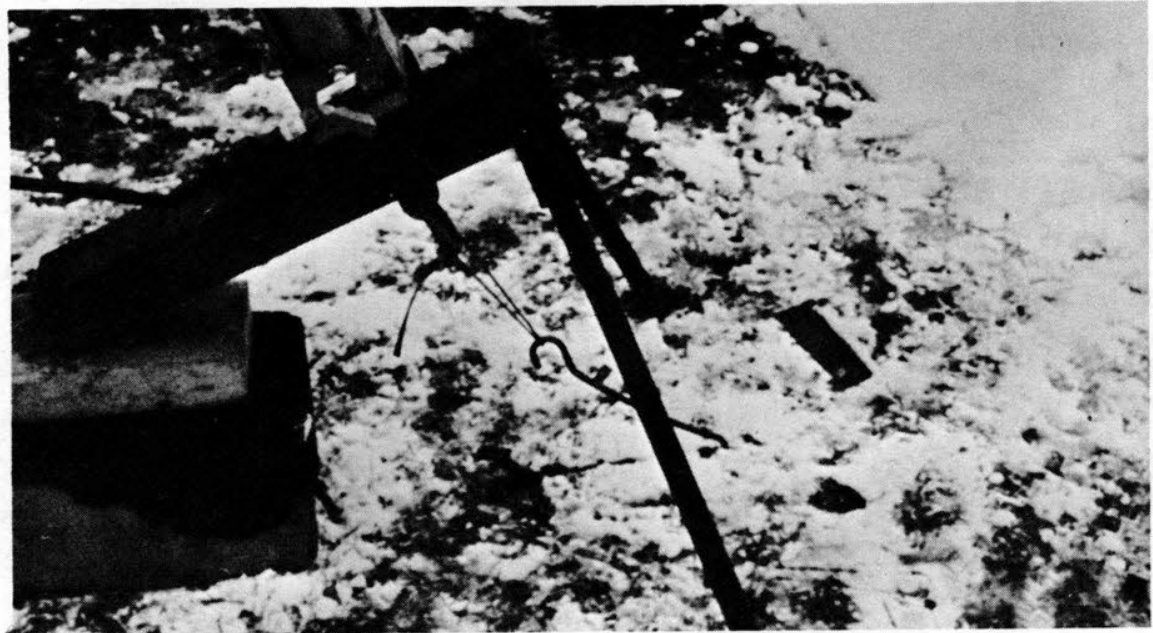

a.
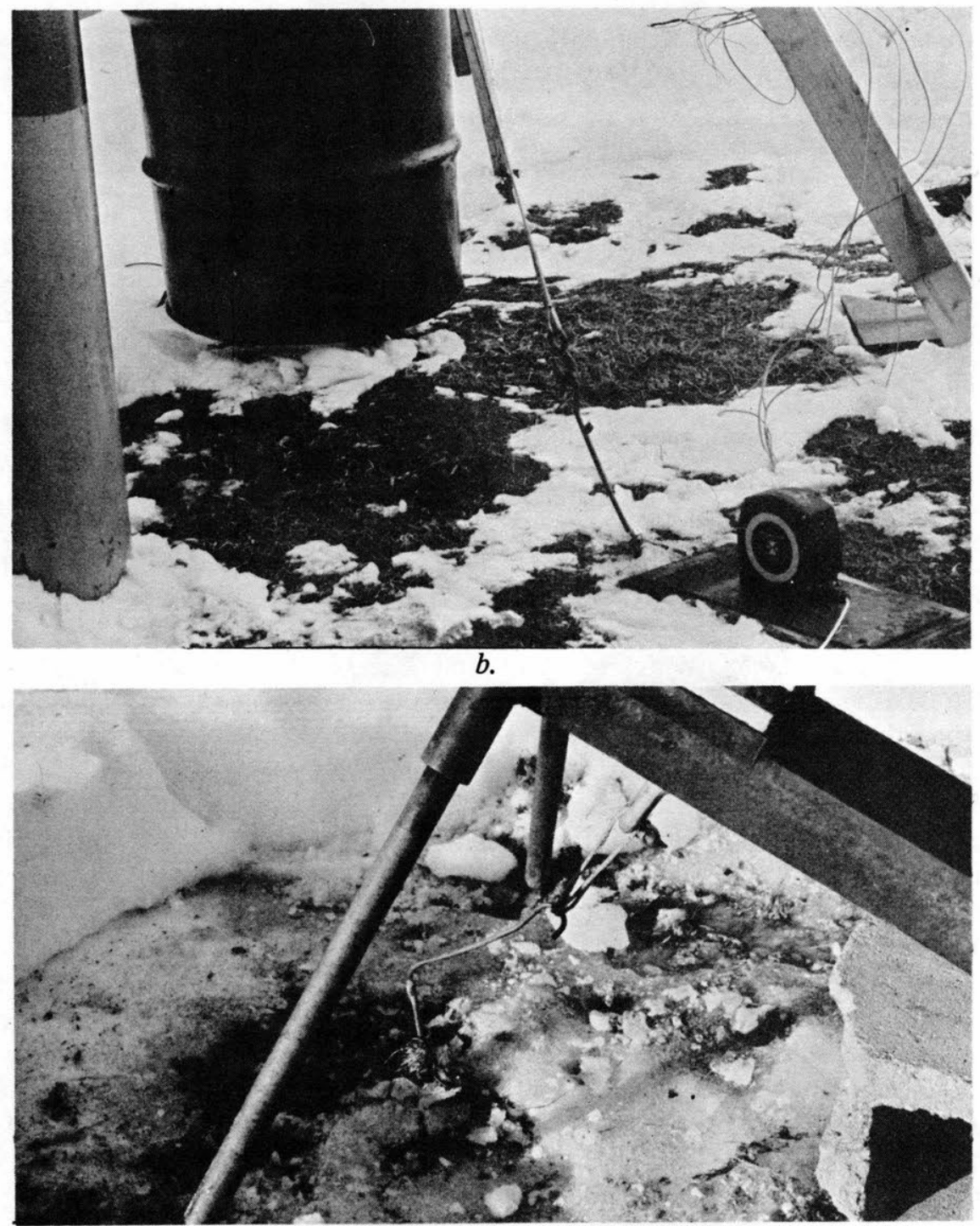

c.

Figure 35. Examples of hook anchor deflection at moderately high loading. 


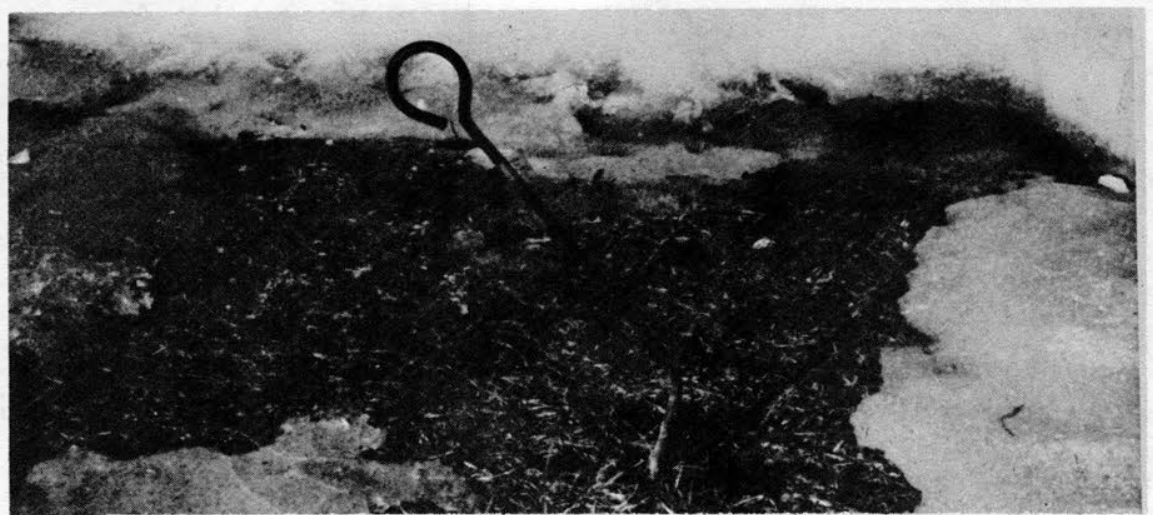

a.

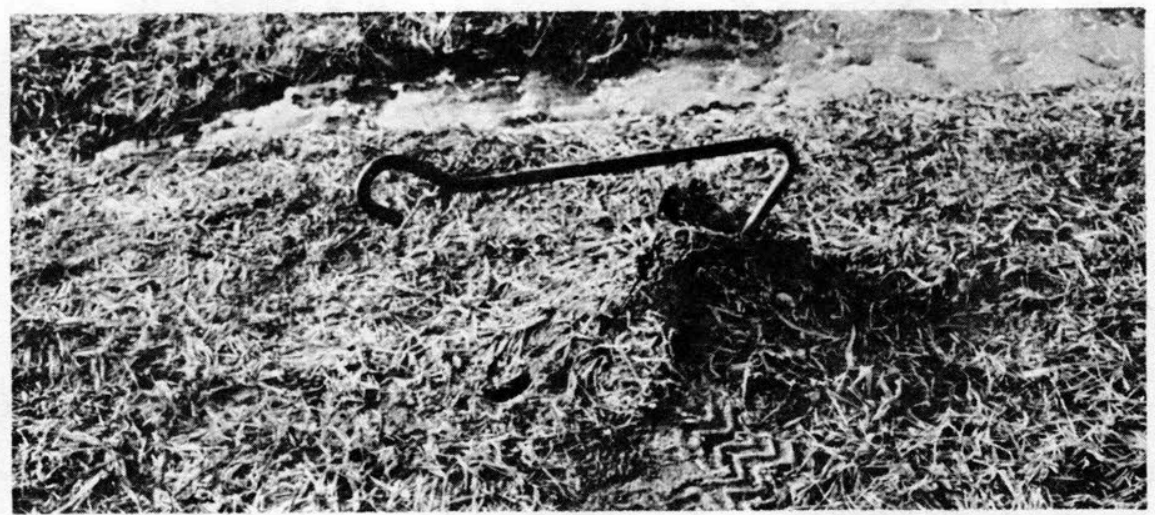

$b$.

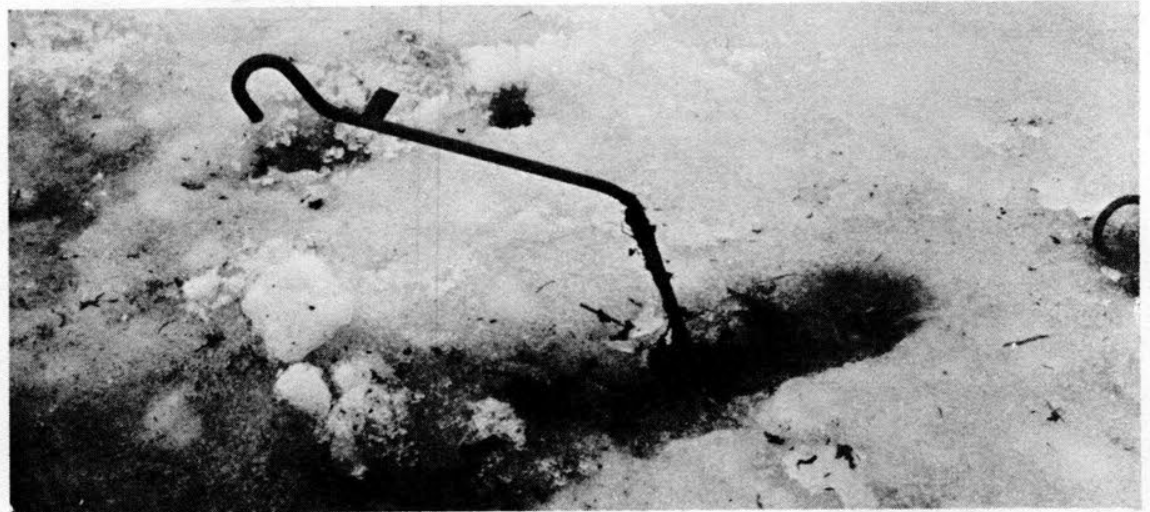

c.

Figure 36. Views of hook anchors not loaded to complete extraction from frozen ground. 


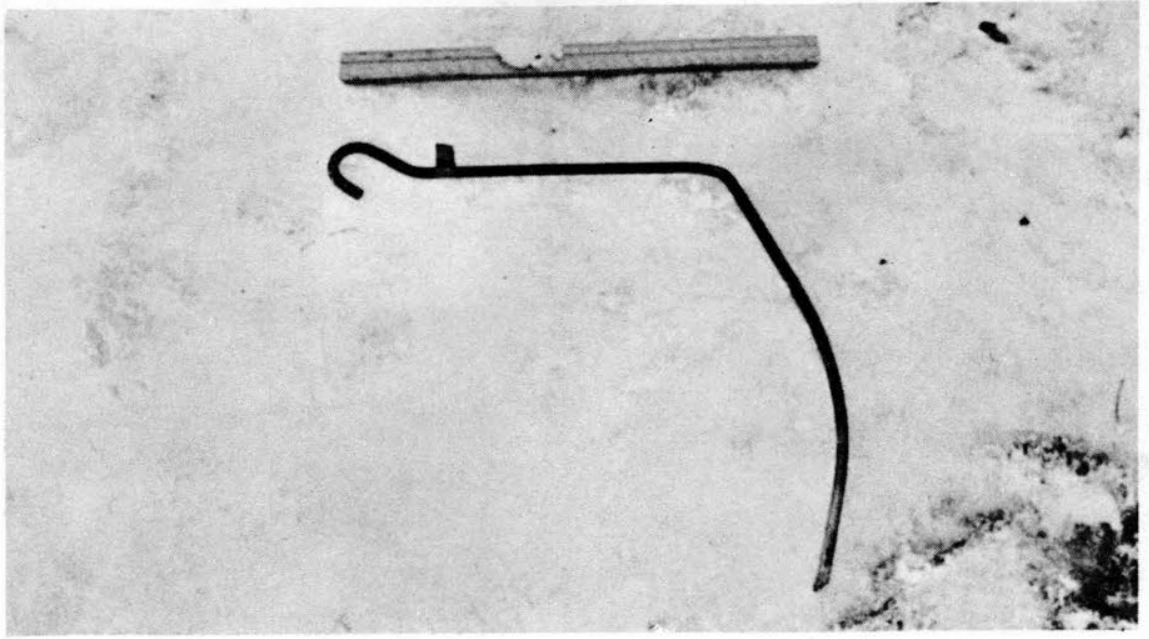

a.

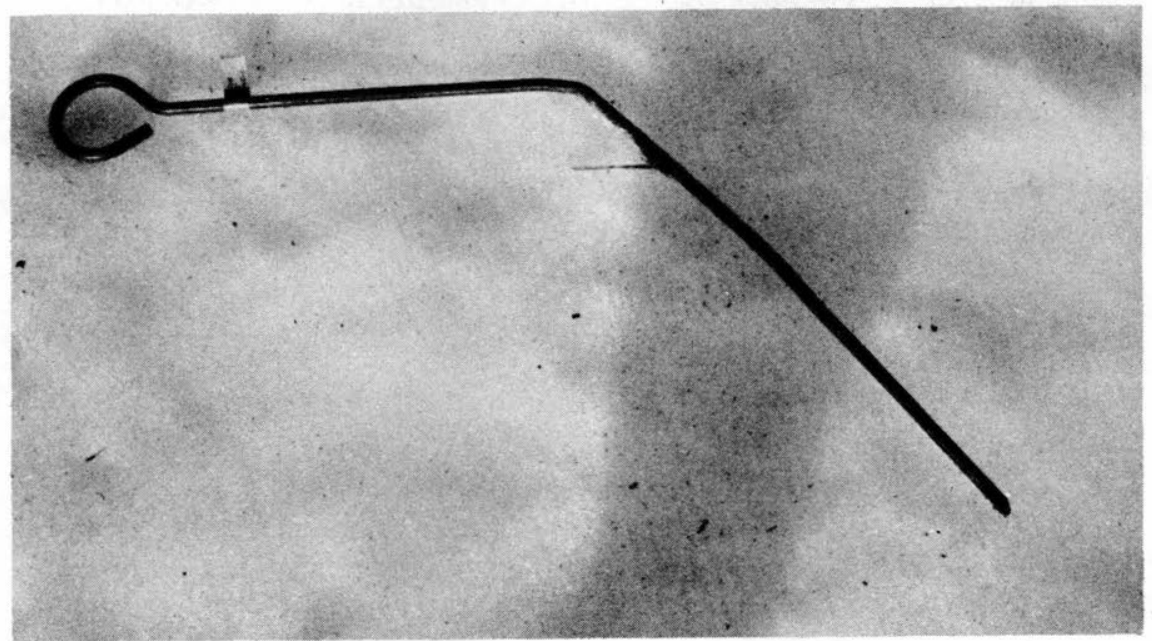

b.

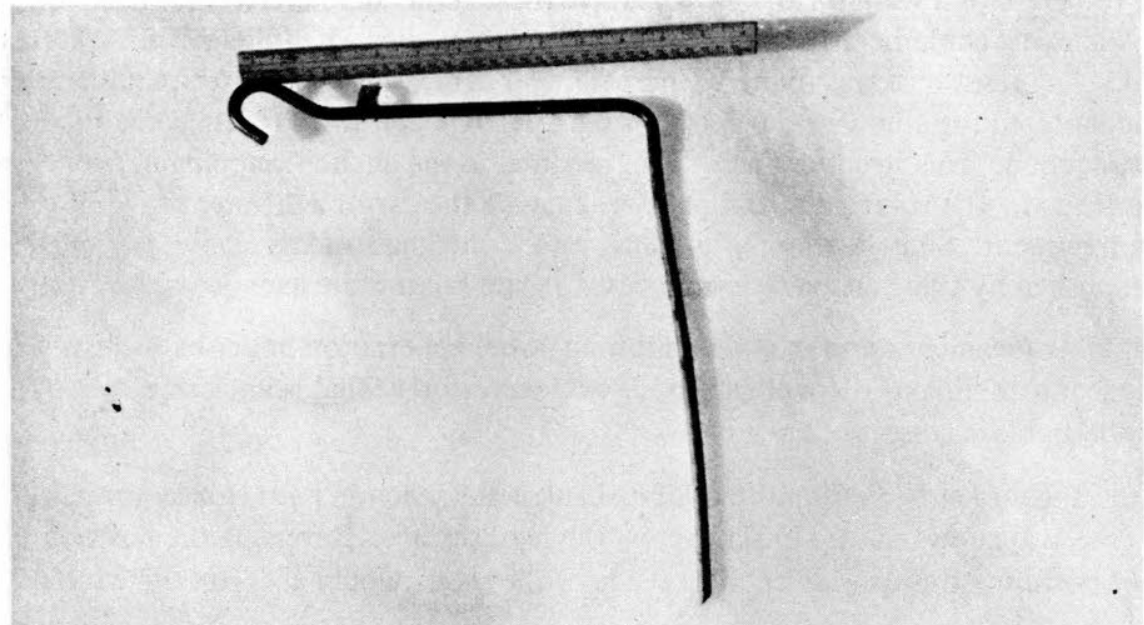

c.

Figure 37. Typical configuration of hook anchors completely extracted from frozen ground. 


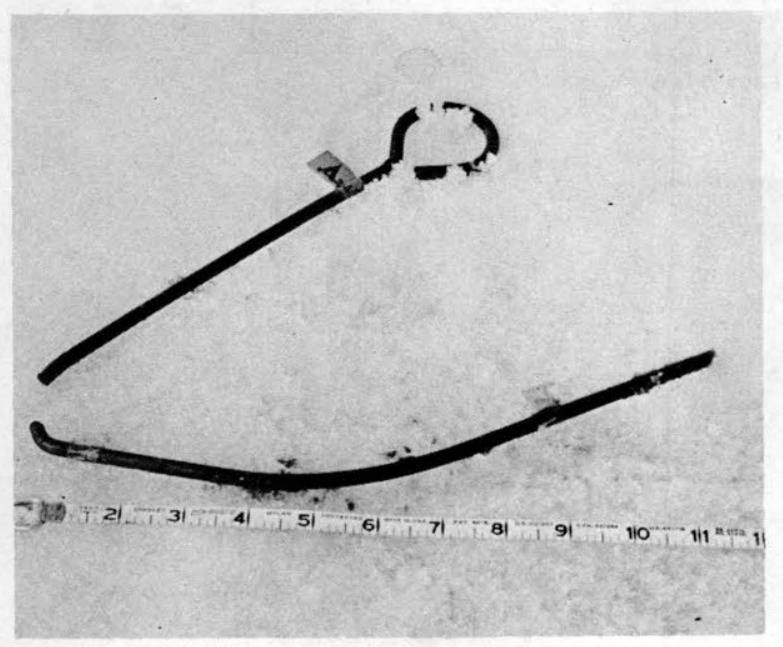

a.

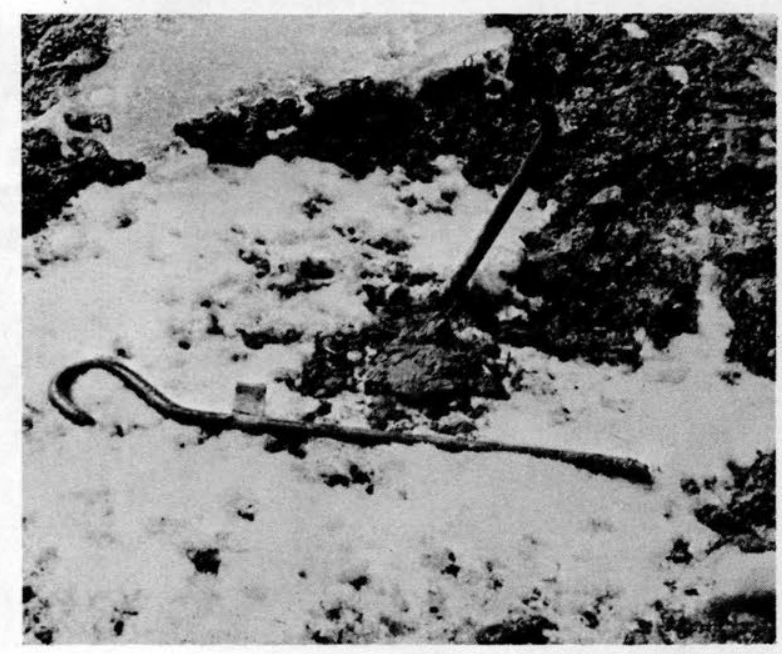

b.

Figure 38. Examples of hook anchors which failed at the elbow when loaded.

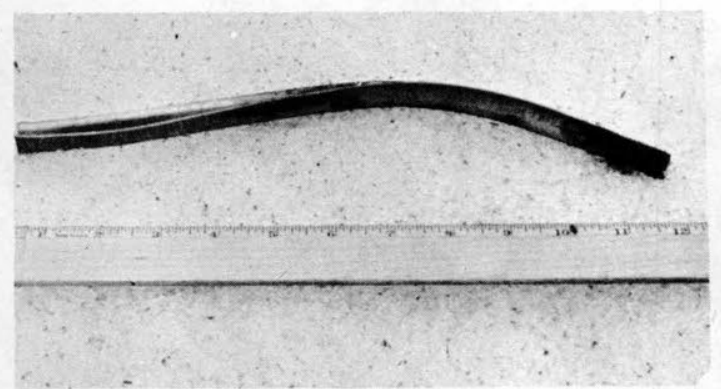

a.

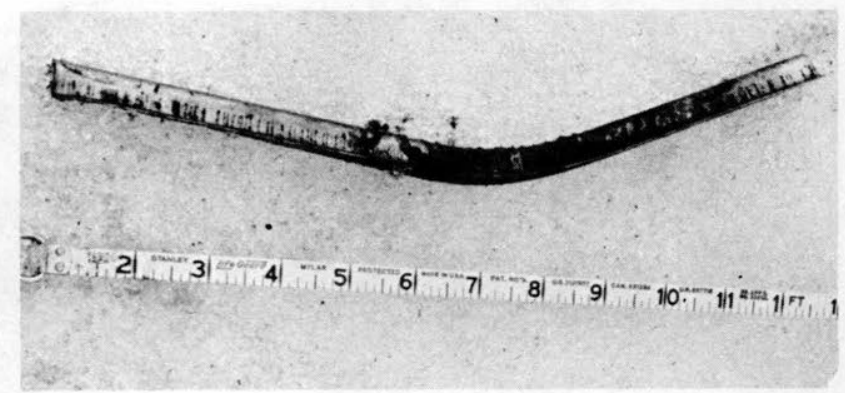

b.

Figure 39. Configuration of GM stakes at the cessation of load testing.

\section{Discussion}

The anchor tests reported were for the most part performed on commercial Anker anchors. It was found that these hook anchors could be driven into the silts of the test sites when the ground temperature was as low as $-5^{\circ} \mathrm{C}$. Driving resistance was found to increase with decreasing ground temperature. When hard ground was encountered the elbow of the anchor would become deformed (peened) by the hard repetitive hammer blows required. This structural weakening resulted in the anchor snapping in half at the elbow when the anchor was loaded. The solution to this problem may be the use of a different type of steel or a different case hardening treatment. Some method of building up the thickness of the elbow may be needed. This could be accomplished by using an extrusion process to manufacture the anchors.

The hand holding the anchor arm in position during initial penetration under hard driving conditions was on occasion subject to a stinging. How this may be avoided or prevented is unclear; a special holding device would be an undesirable accessory.

The tip of the anchor has been found to inhibit shank penetration in hard frozen ground. The present configuration (Fig. 30) allows the tip to skip across the hard surface. Reversing the position of the tip point from its present position on the inside to the outside of the shank would alleviate this problem.

Two views of the hook anchor during actual field use are shown in Figures 40 and 41 . A suggested use of hook anchors for the tiedown of the Canadian Modular tent is shown in Figure 42. Here it is seen that two types of anchors are specified for the tiedown of this shelter. 


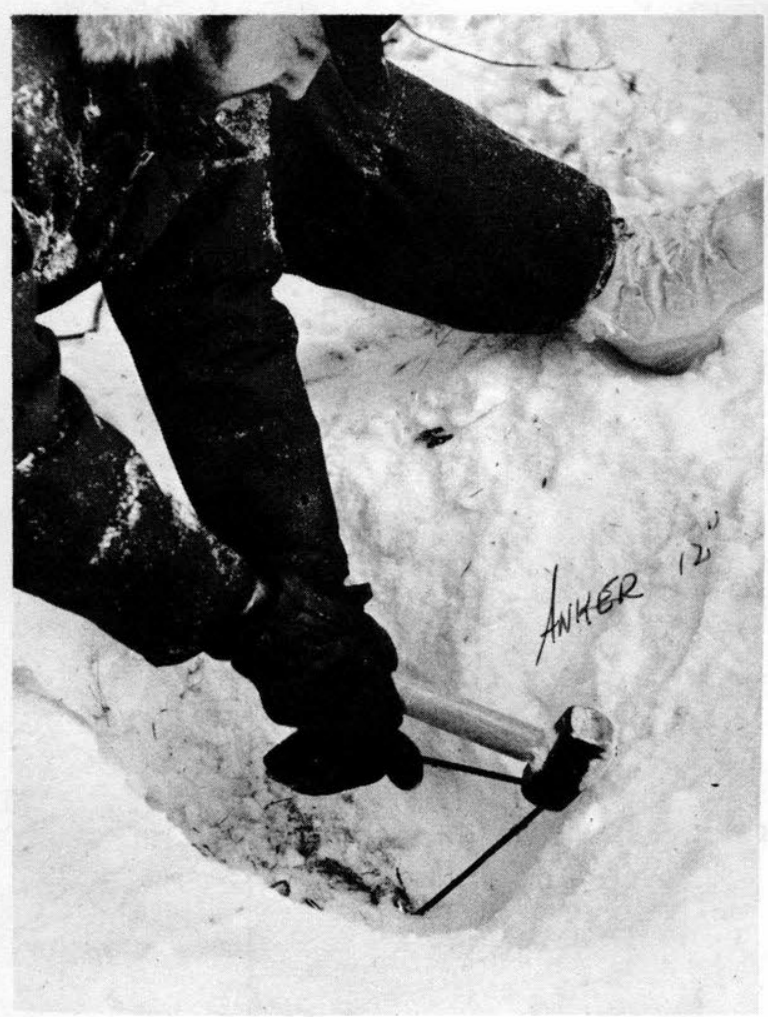

Figure 40. Driving of hook anchor under field conditions.

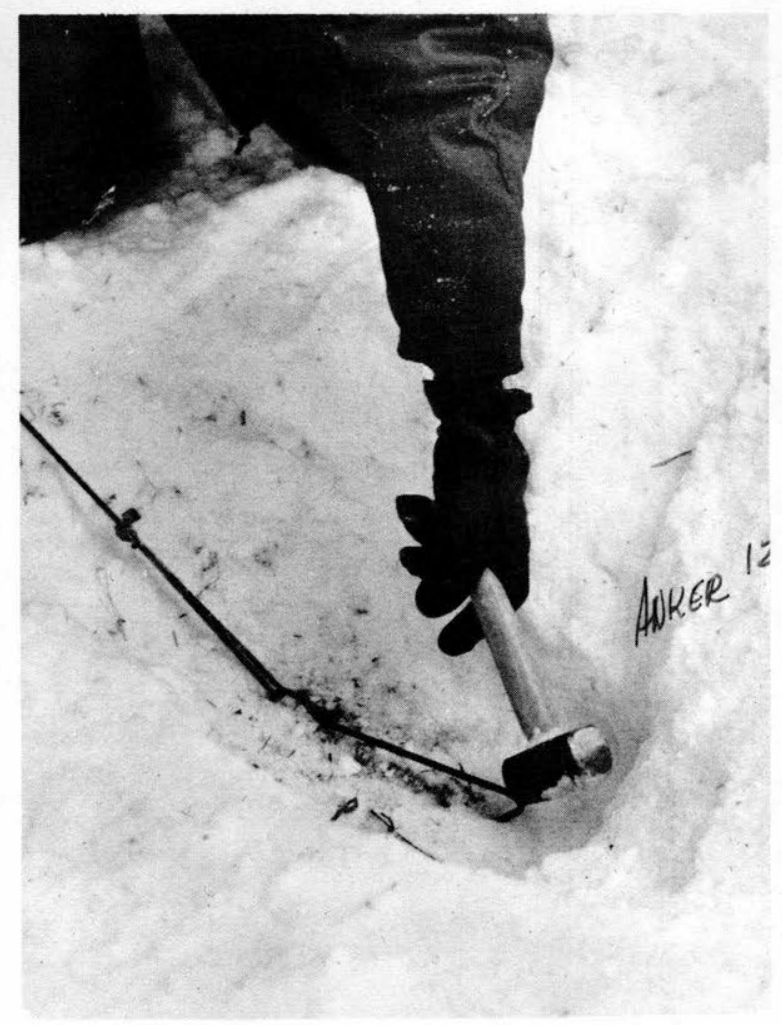

Figure 41. Final drive seating of hook anchor after tent guy has been attached.

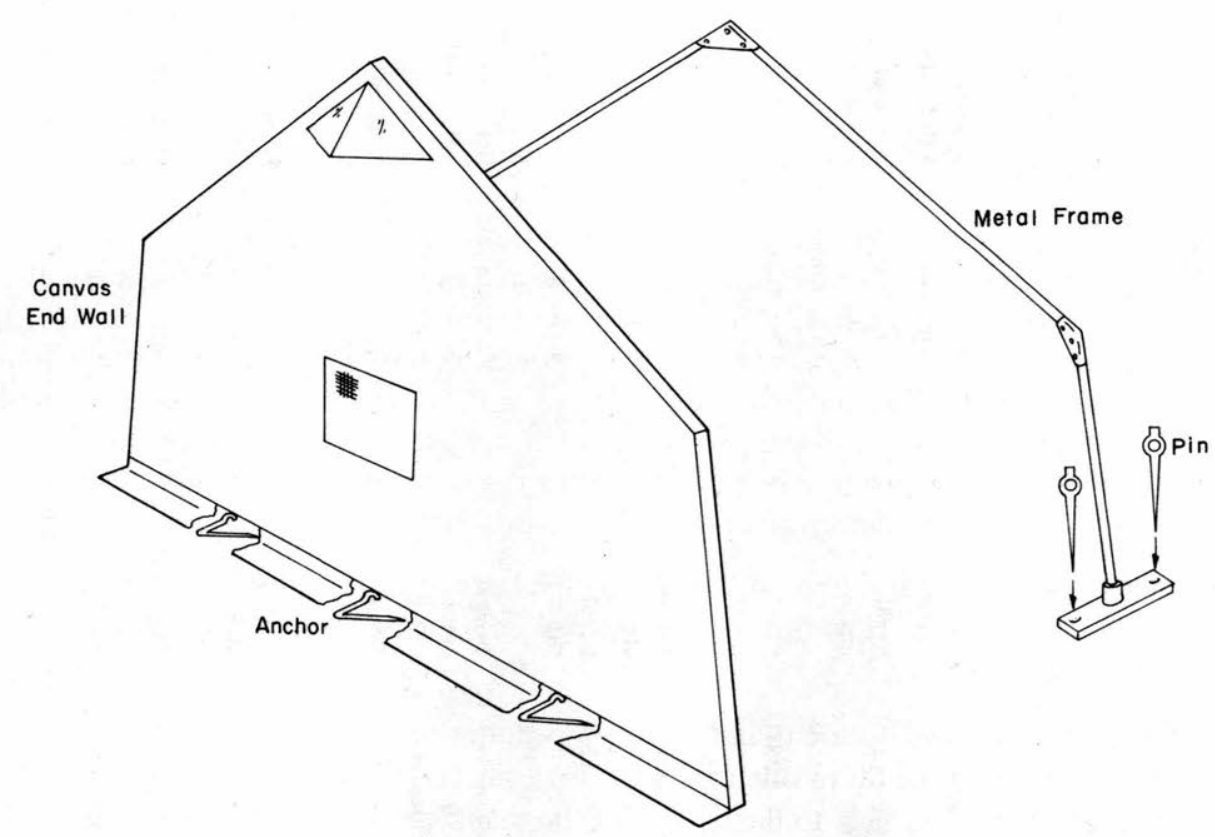

Figure 42. Location of hook anchors used with Canadian Armed Forces Modular tent. 
Table III. Properties of guy stakes and anchors.

\begin{tabular}{|c|c|c|c|c|c|c|c|c|c|c|c|c|c|}
\hline \multirow{3}{*}{$\begin{array}{c}\text { Anchor } \\
\text { type }\end{array}$} & \multirow{3}{*}{$\begin{array}{l}\text { Anchor } \\
\text { material }\end{array}$} & \multirow{3}{*}{$\begin{array}{l}\text { Weight } \\
\text { (lb) }\end{array}$} & \multirow{3}{*}{$\begin{array}{l}\text { Size } \\
\text { (in.) }\end{array}$} & \multirow{3}{*}{$\begin{array}{c}\text { Installation } \\
\text { tool }\end{array}$} & \multirow{3}{*}{$\begin{array}{c}\text { Emplacement } \\
\text { time } \\
\text { (min) }\end{array}$} & \multicolumn{8}{|c|}{ Anchor capacity, $l b$} \\
\hline & & & & & & \multicolumn{8}{|c|}{ Soil class* } \\
\hline & & & & & & $1 A$ & 2 & 3 & 4 & 5 & 6 & 7 & \\
\hline $\begin{array}{l}\text { Stake GP-1 12/G } \\
\text { Stake no. } \\
4030-291-9354\end{array}$ & $\begin{array}{l}\text { Forged } \\
\text { steel }\end{array}$ & 3.6 & $\begin{array}{l}1 \frac{1}{4} \text { diam } \\
17 \text { long } \\
\text { tri-fluted }\end{array}$ & $\begin{array}{l}\text { Hammer } \\
4 \mathrm{lb}\end{array}$ & $1-4$ & 1350 & $\begin{array}{r}1150 \\
790\end{array}$ & $\begin{array}{l}710 \\
525\end{array}$ & $\begin{array}{l}500 \\
500\end{array}$ & $\underline{\underline{310}}$, & & & $\begin{array}{l}\text { Max } \\
\text { creep }\end{array}$ \\
\hline $\begin{array}{l}4 \text { in. Quarter } \\
\text { master }\end{array}$ & $\begin{array}{l}\text { Cast } \\
\text { alum }\end{array}$ & 0.5 & $\begin{array}{l}\text { Arrow head } \\
4 \text { in. sides }\end{array}$ & $\begin{array}{l}\text { Special rod } \\
4 \mathrm{lb} \text { hammer }\end{array}$ & $2-4$ & & $\begin{array}{l}2500 \\
1900\end{array}$ & $\begin{array}{r}1510 \\
935\end{array}$ & $\begin{array}{l}660 \\
590\end{array}$ & & & & $\begin{array}{l}\text { Max } \\
\text { creep }\end{array}$ \\
\hline $\begin{array}{l}\text { Stake GP-1 11/G } \\
\text { Stake no. } \\
4030-097-8670\end{array}$ & $\begin{array}{l}\text { Steel } \\
\text { angle }\end{array}$ & 2.5 & $\begin{array}{l}1^{1 / 4} \times 1^{1 / 4} \\
\times^{3 / 16} \\
18^{1 / 2} \text { long }\end{array}$ & $\begin{array}{l}\text { Hammer } \\
4 \mathrm{lb}\end{array}$ & $1-2$ & & $\begin{array}{r}1450 \\
840\end{array}$ & $\begin{array}{l}860 \\
525\end{array}$ & 650 & 560 & & & $\begin{array}{l}\text { Max } \\
\text { creep }\end{array}$ \\
\hline $\begin{array}{l}\text { Stake GP-108/U } \\
\text { Stake no. } \\
5975-223-4611\end{array}$ & $\begin{array}{l}\text { Steel } \\
\text { angle }\end{array}$ & 8 & $\begin{array}{l}15 / 16 \text { diam } \\
36 \text { long }\end{array}$ & $\begin{array}{l}\text { Sledge } \\
6-8 \mathrm{lb}\end{array}$ & $2-5$ & & $\begin{array}{l}2100 \\
1200\end{array}$ & $\begin{array}{r}1310 \\
950\end{array}$ & 1230 & $\begin{array}{l}950 \\
875\end{array}$ & 680 & 350 & $\begin{array}{l}\text { Max } \\
\text { creep }\end{array}$ \\
\hline $\begin{array}{l}2^{3} / 4 \text { in. screw } \\
\text { commercial }\end{array}$ & $\begin{array}{l}\text { Forged } \\
\text { steel }\end{array}$ & 2 & $\begin{array}{l}1 / 2 \text { diam rod } \\
32 \text { long }\end{array}$ & $\begin{array}{l}\text { Bar } \\
3 / 4 \times 30 \text { in. }\end{array}$ & $4-6$ & & $\begin{array}{l}4020 \\
3700\end{array}$ & $\begin{array}{l}2250 \\
1700\end{array}$ & & $\begin{array}{l}900 \\
660\end{array}$ & & & $\begin{array}{l}\text { Max } \\
\text { creep }\end{array}$ \\
\hline $\begin{array}{l}\text { Stake GP-1 13/G } \\
\text { Stake no. } \\
4030-298-1382\end{array}$ & $\begin{array}{l}\text { Steel } \\
\text { pipe }\end{array}$ & 13 & $\begin{array}{l}13 / 4 \text { diam } \\
46 \text { long }\end{array}$ & $\begin{array}{l}\text { Sledge } \\
8 \mathrm{lb}\end{array}$ & $3-6$ & & $\begin{array}{l}4450 \\
2590\end{array}$ & $\begin{array}{l}2050 \\
1940\end{array}$ & 2625 & $\begin{array}{l}1900 \\
1710\end{array}$ & 1750 & 1425 & $\begin{array}{l}\text { Max } \\
\text { creep }\end{array}$ \\
\hline $\begin{array}{l}3 \text { in. screw } \\
\text { SPO-850 } \\
\text { Sig C Special }\end{array}$ & $\begin{array}{l}\text { Forged } \\
\text { steel }\end{array}$ & 3.3 & $\begin{array}{l}5 / 8 \text { diam rod } \\
36 \text { long }\end{array}$ & $\begin{array}{l}\text { Bar } \\
1 \times 36 \text { in. }\end{array}$ & $5-8$ & & $\begin{array}{l}4010 \\
3500\end{array}$ & $\begin{array}{l}2300 \\
1750\end{array}$ & & $\begin{array}{r}1210 \\
740\end{array}$ & 500 & 230 & $\begin{array}{l}\text { Max } \\
\text { creep }\end{array}$ \\
\hline $\begin{array}{l}\text { Anker (hook) } \\
\text { commercial }\end{array}$ & $\begin{array}{l}\text { Spring } \\
\text { steel }\end{array}$ & 2.7 & $\begin{array}{l}5 / 8 \text { diam rod } \\
18 \text { shank } \\
12 \text { Arm }\end{array}$ & $\begin{array}{l}\text { Hammer } \\
2 \mathrm{lb}\end{array}$ & 1 & & $\frac{1250}{900}$ & & & $\frac{410}{300}$ & & & $\begin{array}{l}\text { Max } \\
\text { creep }\end{array}$ \\
\hline $\begin{array}{l}\text { Anker (hook) } \\
\text { commerical }\end{array}$ & $\begin{array}{l}\text { Spring } \\
\text { steel }\end{array}$ & 2 & $\begin{array}{l}1 / 2 \text { diam rod } \\
18 \text { Shank } \\
15 \text { Arm }\end{array}$ & $\begin{array}{l}\text { Hammer } \\
2 \mathrm{lb}\end{array}$ & 1 & & $\frac{1000}{750}$ & & & $\underline{\underline{300}}$ & & & $\begin{array}{l}\text { Max } \\
\text { creep }\end{array}$ \\
\hline $\begin{array}{l}\text { Grizzly Mint } \\
\text { Stake } \\
\text { commercial }\end{array}$ & $\begin{array}{l}\text { Stamped } \\
1 / 64 \text { in. } \\
\text { steel }\end{array}$ & 0.12 & $\begin{array}{l}\text { Shaped } \\
3 / 4 \text { wide } \\
1 / 2 \text { deep }\end{array}$ & $\begin{array}{l}\text { Hammer } \\
\text { carpenter }\end{array}$ & 1 & & & & & $\frac{100}{\underline{75}}$ & & & $\begin{array}{l}\text { Max } \\
\text { creep }\end{array}$ \\
\hline
\end{tabular}

* See Table IV for soil class description. Load capacities given are averages of limited tests and should be used for guidance only.

1 Estimated. 
Table IV. Simplified soil classification guide.

\begin{tabular}{|c|c|c|}
\hline Class & Type & Description \\
\hline $1 \mathrm{a}$ & Solid ice & \\
\hline 2 & $\begin{array}{l}\text { Shale, sandstone, or soft } \\
\text { rock (solid or in layers). } \\
\text { Coral, frozen ground }\end{array}$ & \\
\hline 3 & Hard pan & $\begin{array}{l}\text { Hard and dry, requires the use of a digging bar or pick mattock } \\
\text { to break the ground. }\end{array}$ \\
\hline 4 & Crumbling, damp & $\begin{array}{l}\text { Consists principally of clay, in a state that will crumble when } \\
\text { an attempt is made to squeeze it into a ball with the hand. }\end{array}$ \\
\hline 5 & Firm, moist & $\begin{array}{l}\text { In many cases, clay is predominant, although the soil may con- } \\
\text { tain small stones, gravel, or sand, and when squeezed with the } \\
\text { hand, forms a firm ball. Most soils in well-drained areas, other } \\
\text { than hillsides, fall into this classification. }\end{array}$ \\
\hline 6 & Plastic, wet & $\begin{array}{l}\text { In most cases, this soil is predominantly clay, as in Class } 5 \text {. Be- } \\
\text { cause of unfavorable moisture conditions, such as areas subject } \\
\text { to heavy seasonal rainfall, sufficient water is present to pene- } \\
\text { trate the soil to a considerable depth, even though the area may } \\
\text { be fairly well drained. During such seasons the solid becomes } \\
\text { plastic and, when squeezed in the hand, readily assumes any } \\
\text { shape into which it is molded. This soil is frequently found in } \\
\text { flat terrains, or near rivers and marshes. }\end{array}$ \\
\hline 7 & Loose, dry & $\begin{array}{l}\text { Usually found in arid regions where sand or gravel predomi- } \\
\text { nates. Filled-in or built-up areas in dry regions, or during very } \\
\text { dry seasons, fall into this classification. Lack of bonding } \\
\text { material to hold the particles together causes the soil to remain } \\
\text { very loose. }\end{array}$ \\
\hline
\end{tabular}

As would be expected the holding capacity of hook anchors was always higher in frozen than in unfrozen ground but varied with anchor diameter and shank length. This is clearly shown in Figure 43. The load capacity given in Figure 43 represents the average maximum failure load applied to hook anchors of a given size. Anchors which failed structurally at the elbow were not included in the calculation.

The frozen ground results presented in Figure 43 were not adjusted for variations in ground temperature nor have the summer data been adjusted for variations in soil moisture content. Differences in the rate of loading or the load increment were not taken into consideration either. These variables are known to influence the load capacity of ground anchors. Nevertheless, the data plotted in Figure 43 show surprisingly little deviation from the rectilinear curve drawn through each set of data.

It is apparent from Figure 43 that for the soil conditions existing during the tests, the maximum capacity of hook anchors in frozen ground is three times that of the same size anchor in the unfrozen ground. It was postulated earlier that the long term load capacity of hook anchors is on the order of two thirds of the anchor's maximum load capacity. If this holds, then Figure 43 can be used as a guide for determining the long term holding capacity of various size anchors in silt.

The Research and Technical Support Activity of the U.S. Army Electronics Command, Fort Monmouth, has compiled information on the properties of a number of guy stakes and anchors. Table III presents the information pertaining to small anchors along with the data from the tests reported herein. The loads obtained from the latter tests are underlined in the table. The data in Table III show that $1 / 2$ - and $5 / 8$-in.-diam hook anchors have a holding capacity comparable to the GP-112/G stake. It is therefore reasonable to assume that the lighter and much cheaper hook anchor (the GP-112/G stake costs nine dollars) could be a substitute for the GP-112/G stake for certain anchoring problems. Further tests would have to be undertaken to verify this assumption. 


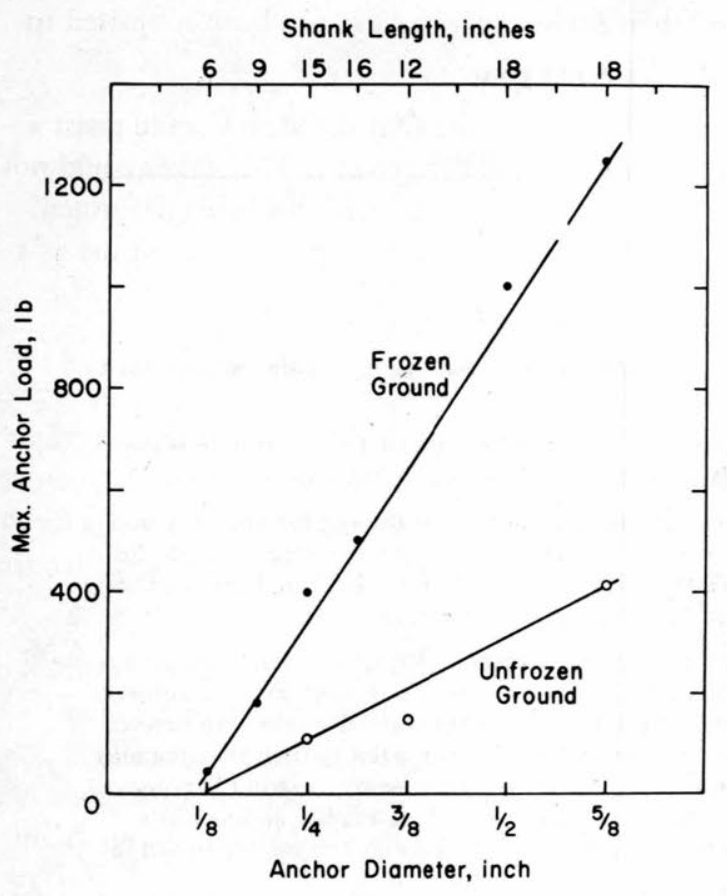

Figure 43. Graphic presentation of test results showing anchor load capacity vs anchor size and vs the frozen and unfrozen ground conditions existing during the tests reported.

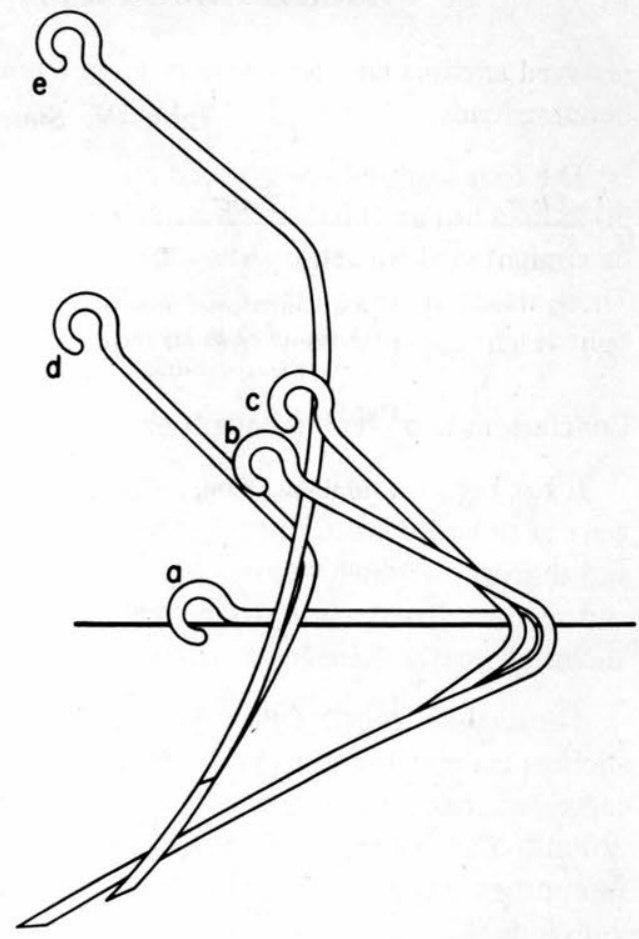

Figure 44. Generalized movement of hook anchors under increased loading. (a) Unloaded positions, (b) initial loading, (c) approximate position at $50 \%$ of maximum load, (d) forward movement and initial upward creep of anchor at $80 \%$ of maximum load, (e) configuration of anchor at time of withdrawal.

While their holding capacity is not doubted, it is questionable whether the GP-108/G stake, the GP-113/G stake, or the $2^{3} / 4$ - and 3-in.-diam screw anchors listed in Table III can be emplaced in the time given or even at all in certain class 2 soils without considerable effort. In particular, the above anchors or stakes can not be emplaced in hard frozen ground without mechanized assistance. Similarly, retrieval from frozen ground would not be possible in many cases without some form of mechanized assistance. Even then, there is a good chance the anchors would suffer permanent damage during extraction. The use of these anchors in hard frozen ground can thus be expected to be restricted. An anchor similar to the hook anchor may offer a suitable substitute.

The flexure and movement of hook anchors under increased loading is shown in Figure 44. When an initial load of about one quarter of the anchor's capacity is applied at an angle of 45 to $60^{\circ}$ the anchor moves from its unloaded position at A to position B. As shown, the anchor arm has raised off the ground, increasing the included angle, and the shank has in fact bent backward. When the load is increased to about one half the anchor's capacity the anchor arm is drawn higher and the shank forward to where it is again straight or now slightly curved forward as shown at position C. At $80 \%$ of the maximum load the anchor shank has been noted to cut into the soil and begin to slip upward as shown in position D. At failure the anchor takes the shape shown in position E as it is withdrawn. After withdrawal the anchor's shank is often found concave inward and the included angle has increased from $45^{\circ}$ to as high as $130^{\circ}$. Although the bent anchors could be restored to their original shape without great difficulty (with the aid of a vice and hammer) it is likely that the anchors were permanently weakened from their ordeal. One must presume that they were and that 
restored anchors will deform and fail at a lower load level than anchors which have not been subjected to bending loads.

The four load tests performed on GM stakes in unfrozen ground revealed that the stakes could resist a $50-1 \mathrm{~b}$ load but at $100 \mathrm{lb}$ they would bend and be quickly extracted from the ground. The stakes could not be straightened for reuse. They also could not be removed from frozen ground without being deformed. These stakes appear suitable for anchoring one- or two-man tents where the guy load is low or for use as a lightweight expendable anchor in frøzen ground.

\section{Conclusions and recommendations}

It has been found that hook anchors can be driven and retrieved from frozen silt (soil test temperatures were at or above $-5^{\circ} \mathrm{C}$ ) and that the anchors have a reasonable holding capacity for their size in both frozen and unfrozen ground. As would be expected, anchor capacity increased with shank length and diameter and with increased soil resistance due to freezing. It was found that anchor capacity was more sensitive to anchor diameter than shank length for the anchors tested.

The anchors appear particularly suited for use in hard or frozen ground where the driving and retrieval of anchors is often found to be a difficult task. Even though refinements to the anchor are in order, it is suggested that the commercially available anchors be tried at this time by USARAL troops under field conditions. Their findings will supplement the findings of this report and hopefully provide suggestions on how to improve the anchor's performance. The size of the hook anchor suggested for field trial is $5 / 16$ in. diam, 9-in.-long shank and 7inn.-long arm. 